\title{
Optimal Heat Transfer Coefficient Distributions during the Controlled Cooling Process of an H-Shape Steel Beam
}

\author{
Yu-Feng Gan and Jiin-Yuh Jang \\ Department of Mechanical Engineering, National Cheng Kung University, Tainan 70101, Taiwan \\ Correspondence should be addressed to Jiin-Yuh Jang; jangjim@mail.ncku.edu.tw
}

Received 29 June 2017; Accepted 17 August 2017; Published 27 September 2017

Academic Editor: Frederic Dumur

Copyright (c) 2017 Yu-Feng Gan and Jiin-Yuh Jang. This is an open access article distributed under the Creative Commons Attribution License, which permits unrestricted use, distribution, and reproduction in any medium, provided the original work is properly cited.

\begin{abstract}
Three-dimensional thermal-mechanical models for the prediction of heat transfer coefficient distributions with different size beams are investigated. $\mathrm{H} 300 \times 300, \mathrm{H} 250 \times 250$, and $\mathrm{H} 200 \times 200 \mathrm{H}$-shape steel beams are investigated in a controlled cooling process to obtain the design requirements for maximum uniform temperature distributions and minimal residual stress after controlled cooling. An algorithm developed with the conjugated-gradient method is used to optimize the heat transfer coefficient distribution. In a comparison with the three group results, the numerical results indicate that, with the same model and under the same initial temperature $\left(T=850^{\circ} \mathrm{C}\right)$ and final temperature $\left(T=550 \pm 10^{\circ} \mathrm{C}\right)$, the heat transfer coefficients obtained with the conjugatedgradient method can produce more uniform temperature distribution and smaller residual web stress, with objective functions of the final average temperature $T_{\text {ave }} \pm \Delta T$ and maximum temperature difference to minimum $\min \left\{\Delta T_{\max }(x, y)\right\}$. The maximum temperature difference is decreased by $57^{\circ} \mathrm{C}, 74^{\circ} \mathrm{C}$, and $75^{\circ} \mathrm{C}$ for Case 1 , Case 2, and Case 3, respectively, the surface maximum temperature difference is decreased by $60 \sim 80^{\circ} \mathrm{C}$ for three cases, and the residual stress at the web can be reduced by $20 \sim 40 \mathrm{MPa}$ for three cases.
\end{abstract}

\section{Introduction}

H-shape steel beams are widely utilized in industry and on construction sites due to their safety characteristics and the fact that they are economic cross-section steel with a wide flange, thin web, and superior cross-section properties [1,2]. $\mathrm{H}$-shape steel beams have uneven temperature distribution in the cooling process due to their complex geometry, which probably produces warping and breaking, so controlled cooling plays a very important role after rolling to obtain highperformance, high-strength $\mathrm{H}$-beams.

As early as the late 1950s and 1960s, studies on the improvement of the mechanical properties of steel were performed mostly in Europe, where in particular, such studies were being performed actively in the BISRA (British Iron and Steel Research Association). Then, at the end of the 1970s, accelerated cooling equipment was first installed in a Japanese steel mill to provide high-strength, high-toughened steel [3]. JFE Steel developed TMCP (thermomechanical control process) technology in 1980, which is a microstructural control technique combining controlled rolling and cooling [4]. In 1998, JFE Steel developed Super-OLAC, an advanced accelerated cooling system capable of cooling plates homogeneously at high cooling rates close to the theoretical limits [5].

Recently, there have been many researchers committed to controlling the temperature distribution and the temperature differences occurring in the cooling process through simulations and experiments intended to improve steel mechanics. In 2003, Liu et al. [6] studied the heat transfer boundary conditions and analyzed the distribution and changes in the temperature field of $\mathrm{H}$-beams during the cooling process, and their results were compared with the available experimental data. In 2008, Liu et al. [7] analyzed the temperature field of H-beams during cooling using a numerical simulation and discussed the temperature distribution and character in different parts of the beams during both air cooling and spray cooling. It was found that the appropriate cooling mode can obtain a fairly uniform temperature field and thus improve the steel mechanical properties. Zhao et al. [8] focused on 
how to improve H-beam cooling distortion and discussed the uneven temperature distribution occurring in the cooling process causing uneven distortion phenomenon in an $\mathrm{H}$ beam cross-section.

In 2013, Guo et al. [9] analyzed temperature fields during both controlled cooling and air cooling and the microstructural mechanical properties for different parts of an H-beam after it was control cooled for $4.5 \mathrm{~s}$, and the lowest and the highest temperature were measured at the edge of the flange and at the $\mathrm{R}$ corner, respectively. The microstructure for the different parts of the $\mathrm{H}$-beam consisted of ferrite and pearlite, and the grain size at the $\mathrm{R}$ corner was coarser than that at the flange and web. The changes in the microstructure were in good agreement with those of the temperature field, and the results indicated that the uniformity of the microstructure and mechanical properties can be improved by increasing the water flow rate at the R corner. In 2014, Ma et al. [10] designed four kinds of cooling schemes with spray cooling to probe the transient temperature field and the stress field, which have different water flow rate at different parts of an H-beam, and it was found that the main reason for residual thermal stress is section temperature differences in the $\mathrm{H}$-shape steel beam during cooling process after rolling.

There have been many studies discussing simulations of a thermal stress field. In 2008, Zhu et al. [11] simulated the thermal residual stress field of $\mathrm{H}$-beams with different lengths using air cooling, where the results indicated that the residual stress at the web exhibited compressive stress, while that at the web center and the fillet exhibited tensile stress. The residual stress condition in the direction of the width influenced the distribution of the residual stress in the direction of the length. Liu et al. (2008) [12] considered heat transfer and the thermoelastic plastic theory together with the finite element method to simulate the temperature and the thermal stress of an H-beam during the cooling process and found that the appropriate cooling mode and parameters can effectively enable the acquisition of a fairly uniform temperature field and lower residual stress. In 2011, Zhao et al. [13] analyzed the distribution of the stress and strain field under different thermal boundary and cooling time conditions, and their results showed that the temperature of an $\mathrm{H}$-beam will decrease with increases in the density of the water flow, and the maximum stress will increase. In the same year, Zhu et al. [14] simulated the residual stress distribution of hot rolled $\mathrm{H}$-beams after cooling and the transformations in residual stress during flange cutting. Jang and Gan [15] recently proposed an algorism to calculate the optimum heat transfer coefficient combination for an H-beam.

Based on previous studies, it can be inferred that the temperature field significantly affect the stress of H-beams. Therefore, the heat transfer coefficients of an H-beam as the thermal boundary condition are very important operating parameters to control the temperature field. In order to optimize the temperature field and temperature differences, optimization of the heat transfer coefficients is investigated and solved numerically using a commercial CFD code ANSYS FLUENT solver along with the conjugate-gradient method (CGM) that has been successfully applied to other applications [16-19]. The design variables in the present study are the heat transfer coefficients, which strongly affect the temperature field and the residual stress field of an H-beam. The optimal temperature field and stress field with the heat transfer coefficients are thus determined using the developed optimization algorithm.

\section{Mathematical Analysis}

In this work, the controlled cooling process of H-beams from the China Steel Corporation (CSC), Taiwan, is simulated via transient heat transfer using a three-dimensional model to control cooling after the rolling process. The H-beams are composed of three parts, the web, flange, and fillet, for which the physical model and the grid meshing are shown in Figures 1 and 2 . Three sizes of $\mathrm{H}$-beam models have been established, and the sizes of the H-beams $(\mathrm{H} 300 \times 300, \mathrm{H} 250 \times 250$, and $\mathrm{H} 200 \times 200$ ) are listed in Figure 1, which correspond to Case 1, Case 2, and Case 3 in this paper, respectively. The H-beams used in this study were a high strength, low alloy steel ASTM A572 beam. Based on the cooling and the geometrical characteristics of the H-beams, symmetry physical models were built which symmetry with $x$-axis, $y$ axis, and $z$-axis, respectively, and the controlled cooling of the H-beams was divided into five parts corresponding to the heat transfer coefficients $h_{1}, h_{2}, h_{3}, h_{4}$, and $h_{5}$, as shown in Figure 3. In this research, two approaches were used to obtain the objective temperature fields of the H-beams, where one adopted the constant heat transfer coefficients and the other one adopted the CGM search for the optimal heat transfer coefficients as the boundary condition by which to compare the temperature fields and stress fields with the same average cooling temperature.

2.1. Governing Equations. The following transient heat conduction equation governs the temperature field of an $\mathrm{H}$-beam [20]:

$$
\frac{\partial}{\partial x_{j}} k\left(\frac{\partial T}{\partial x_{j}}\right)=\rho \cdot C p \frac{\partial T}{\partial t}
$$

where $\rho, C p$, and $k$ are the density, heat capacity, and thermal conductivity of the $\mathrm{H}$-beam, respectively. The phase transformation occurs at $T=550^{\circ} \mathrm{C}$, which brings latent heat and internal stress. These effects are considered in the variations of thermal-mechanical physical properties (specific heat, thermal conductivity, thermal expansion coefficient, Young's modulus, and yield stress) with temperature as shown in Figure 4 [21]. The diagrams of the variation in microstructures are also shown in Figure 4(d). The density $\rho$ is a constant equal to $7750 \mathrm{~kg} / \mathrm{m}^{3}$ and the initial temperature of the H-beam is assumed to be uniform at $850^{\circ} \mathrm{C}$.

The incremental theory of plasticity governs the residual stress field of an H-beam. The plastic deformation of the materials is assumed to obey the von Mises yield criterion and the associated flow rule. The relationship of the rate components between thermal stresses, $\sigma_{i j}$, and strains, $\varepsilon_{i j}$, is described by [20] 

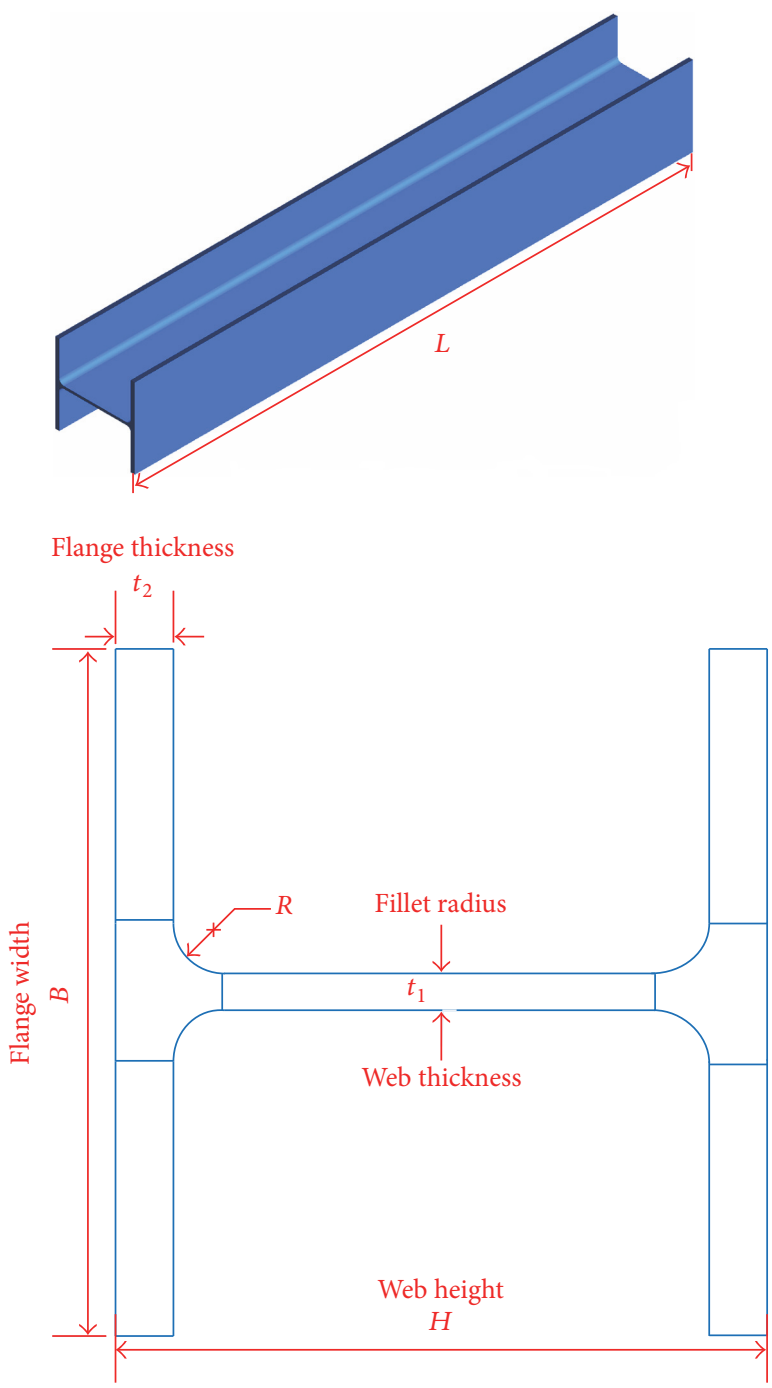

\begin{tabular}{lcccccc}
\hline Size & $\begin{array}{c}\text { Web height } \\
H(\mathrm{~mm})\end{array}$ & $\begin{array}{c}\text { Flange width } \\
B(\mathrm{~mm})\end{array}$ & $\begin{array}{c}\text { Web thickness } \\
t_{1}(\mathrm{~mm})\end{array}$ & $\begin{array}{c}\text { Flange thickness } \\
t_{2}(\mathrm{~mm})\end{array}$ & $\begin{array}{c}\text { Radius } \\
R(\mathrm{~mm})\end{array}$ & $\begin{array}{c}\text { Length } \\
L(\mathrm{~mm})\end{array}$ \\
\hline Case 1 & 300 & 300 & 10 & 15 & 13 & 1500 \\
Case 2 & 250 & 250 & 9 & 14 & 13 & 1200 \\
Case 3 & 200 & 200 & 8 & 12 & 13 & 1000 \\
\hline
\end{tabular}

Figure 1: The physical model.

$$
\begin{aligned}
\dot{\varepsilon}_{i j}= & \frac{1+v}{E} \dot{\sigma}_{i j}-\frac{v}{E} \dot{\sigma}_{k k} \delta_{i j}+\lambda s_{i j} \\
& +\left[\alpha+\frac{\partial \alpha}{\partial T}\left(T_{s}-T_{\infty}\right)\right] \dot{T}, \\
s_{i j}= & \sigma_{i j}-\frac{1}{3} \sigma_{k k} \delta_{i j}, \\
\sigma_{e}= & \left(\frac{3}{2 s_{i j} s_{i j}}\right)^{1 / 2}, \\
d \lambda= & \frac{3 d \varepsilon_{i}}{2 \sigma_{i}},
\end{aligned}
$$

where $E$ is Young's modulus; $v$ is the Poisson's ratio; $\alpha$ is the thermal expansion coefficient; $s_{i j}$ are the component of deviatoric stresses; and $\lambda$ is the plastic flow factor. $\lambda=0$ for elastic deformation or $\sigma_{e}<\sigma_{s}$, and $\lambda>0$ for plastic deformation or $\sigma_{e} \geq \sigma_{s}$, where $\sigma_{s}$ is the yield stress and $\sigma_{e}$ is the von Mises effective stress. Poisson's ratio $v$ is a constant equal to 0.3 , where Young's modulus $E$, the thermal expansion coefficient $\alpha$, and the yield stress $\sigma_{s}$ vary with the temperature and have similar significantly change in about $550^{\circ} \mathrm{C}$ with the heat capacity and the thermal conductivity, as shown in Figures 4(b) and 4(c) [20]. The initial residual stress of the $\mathrm{H}$-beam is assumed to be uniform and equal to zero. 


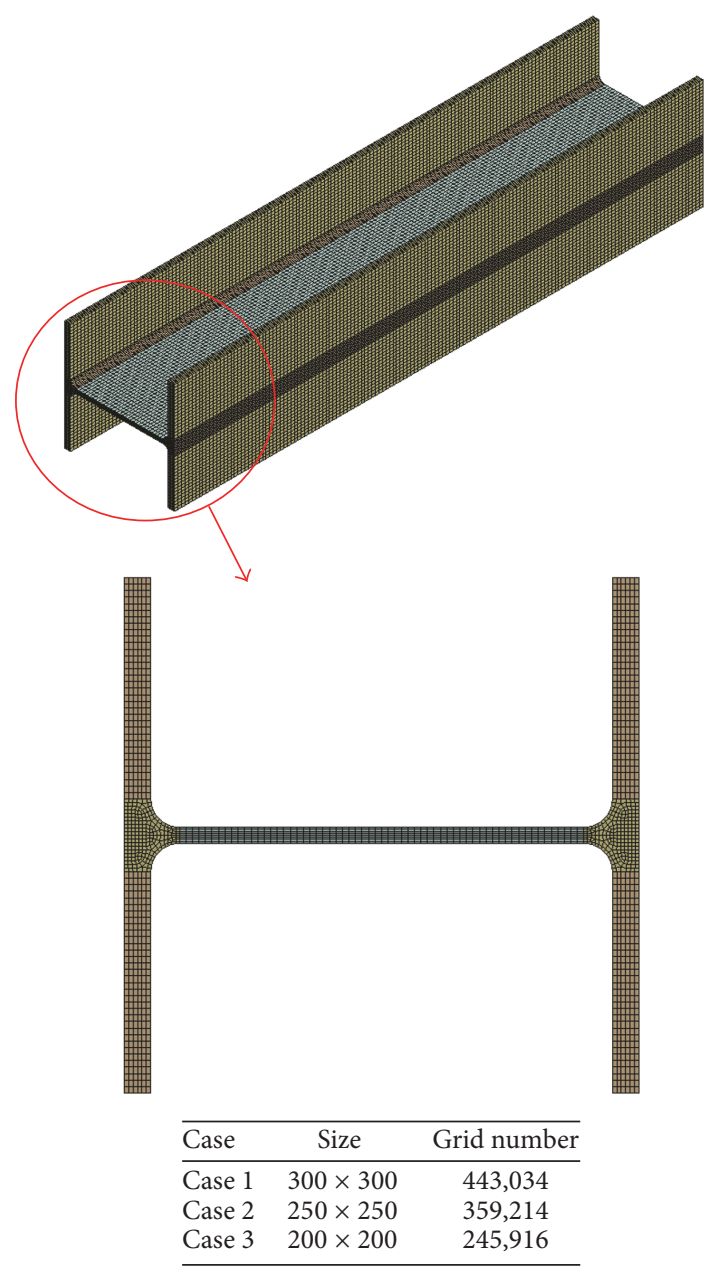

Figure 2: The meshing grid of the physical model.

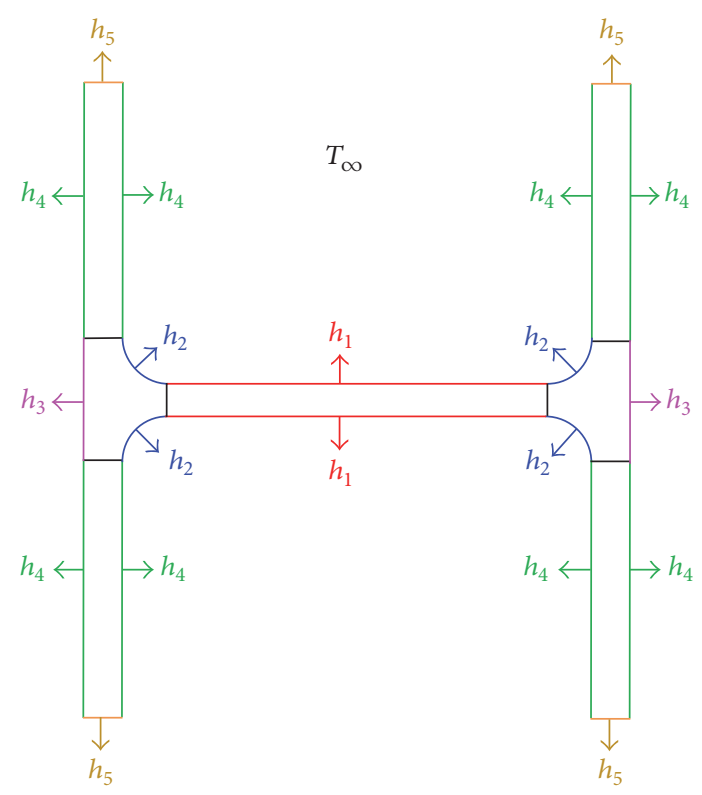

FIgURE 3: The heat transfer coefficients distribution.
2.2. Initial and Boundary Conditions. The convective heat transfer between the H-beams surface and the surroundings is evaluated by using the equation

$$
q^{\prime \prime}=-\left.k \frac{\partial T}{\partial n}\right|_{\text {surface }}=h\left(T_{s}-T_{\infty}\right)
$$

where $h$ is the convective heat transfer coefficient for the surface of the H-beam and varies with the different parts of the H-beam. In addition, $T_{s}$ is the surface temperature of the $\mathrm{H}$-beam, and $T_{\infty}$ is the environmental temperature of $25^{\circ} \mathrm{C}$ in the water cooling and air cooling process. The cooling conditions require water cooling for $15 \mathrm{~s}$ and then air cooling to the ambient temperature (about 100 minutes), where the water cooling rate is about $20^{\circ} \mathrm{C} / \mathrm{s}$, the air cooling heat transfer coefficient is $30 \mathrm{~W} / \mathrm{m}^{2} \mathrm{~K}$, and the water cooling heat transfer coefficients are determined by the constant and optimization values of the CGM.

\section{Numerical Method}

3.1. Numerical Algorithm. In this study, the commercial software ANSYS is adopted to solve the governing equations and the finite element method is used to simulate the temperature field and the thermomechanical analysis. The computation process is transient, so the first-order implicit method was adopted to maintain the numerical stability of every time step. The time step was $0.1 \mathrm{~s}$ for the CGM and the program controlled for thermomechanical analysis to satisfy the requirements of the computational accuracy. The computational grids for the three-dimensional models, which are composed of 3,544,272, 107,848, and 94,248 cells for Case 1, Case 2, and Case 3, respectively, were typically adopted in the computational domain, as shown in Figure 2 and Table 2. However, a careful check of the grid independence of the numerical solutions was made to ensure the accuracy and validity of the numerical results. For this purpose, the symmetry model grid systems were tested, which comprised 541,323, 443,034, and 295,556 cells for Case 1,394,611, 359,214, and 262,200 cells for Case 2, and 385,120, 245,916, and 129,276 cells for Case 3 , respectively. It was found that the relative errors under the same conditions among the temperature solutions obtained with three types of grids were less than $0.5 \%$ for the three cases. The discretized system was solved iteratively until it satisfied the following residual convergence criterion.

$$
\max \left(\frac{\left|T_{i, j}^{n}-T_{i, j}^{n-1}\right|}{T_{i, j}^{n}}\right) \leq 10^{-6}
$$

where $T_{i, j}^{n-1}$ is the previous temperature value of $T_{i, j}^{n}$ at the same time level.

The simulations were performed as a parallel calculation using sixteen core central processing units for the threedimensional models. The computer computation times were approximately 10, 8, and 6 minutes for each search step for Case 1, Case 2, and Case 3, respectively. 


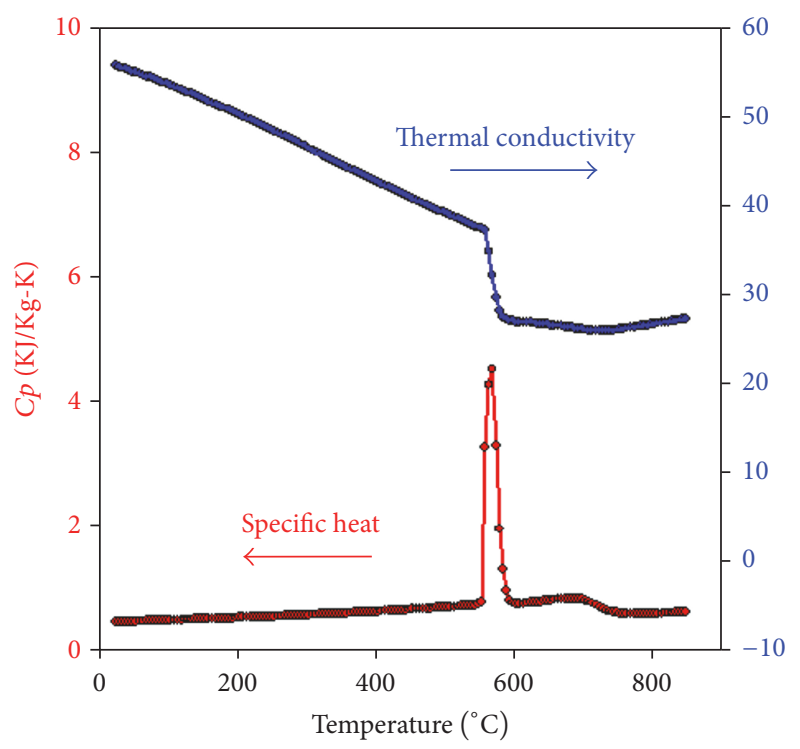

(a) Specific heat and thermal conductivity

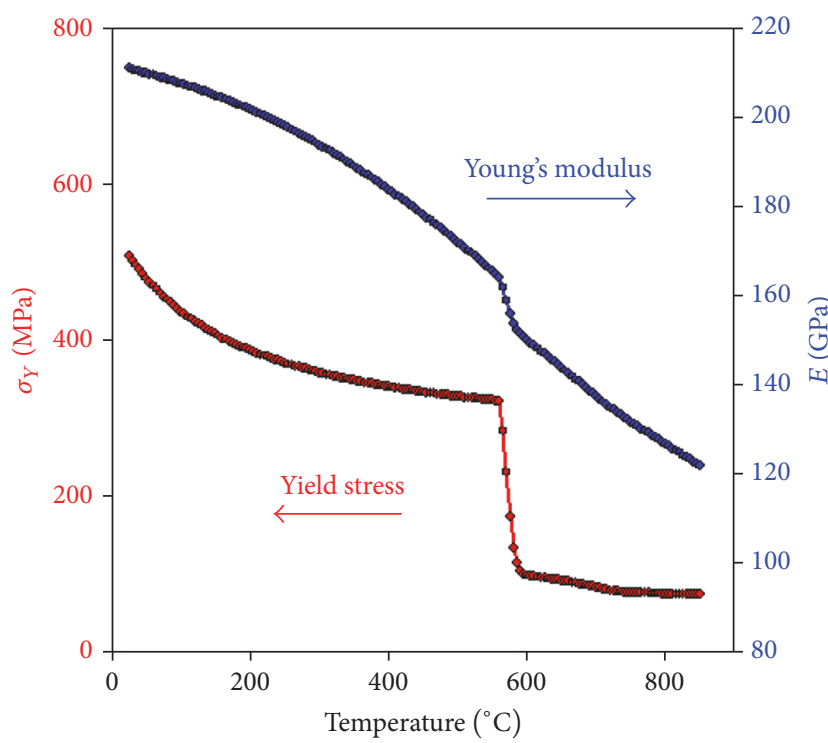

(c) Young's modulus and yield stress

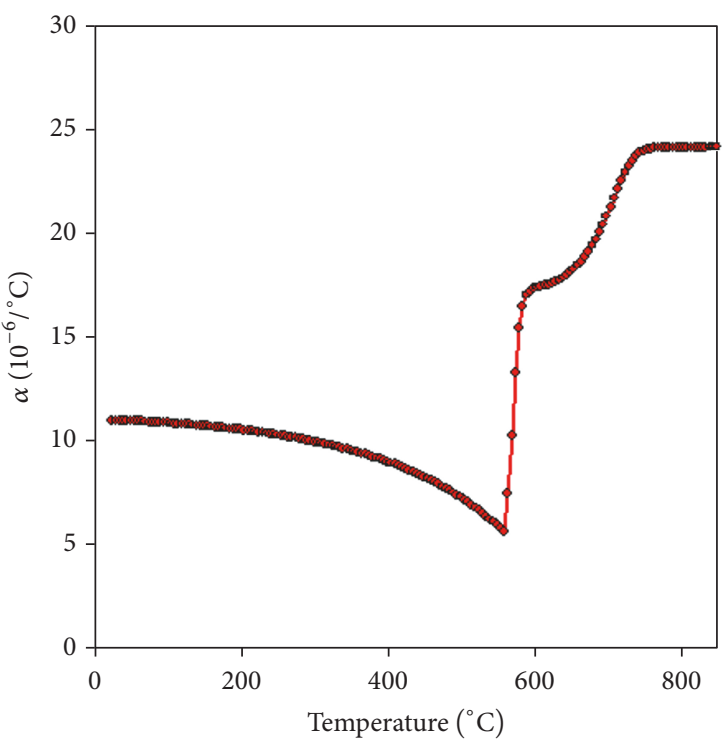

(b) Thermal expansion

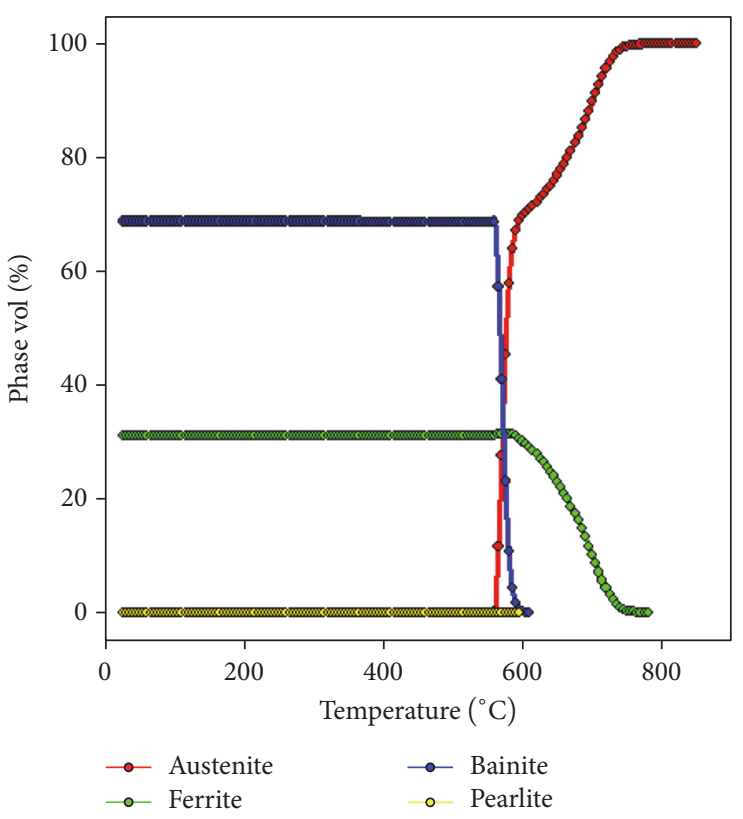

(d) Phases volume

FIGURE 4: Variations in the thermal-mechanical properties with temperature.

3.2. Optimization. In this study, the conjugate-gradient method (CGM) was combined with a finite volume method (FVM) code as an optimizer to search for the optimum heat transfer coefficients $\left(h_{1}, h_{2}, h_{3}, h_{4}, h_{5}\right)$. The objective functions $J_{1 \mathrm{obj}}\left(h_{1}, h_{2}, h_{3}, h_{4}, h_{5}\right)$ and $J_{2 \mathrm{obj}}\left(h_{1}, h_{2}, h_{3}, h_{4}, h_{5}\right)$ were defined as the range of the final average temperature $\left(T_{\text {ave }} \pm\right.$ $\delta=550 \pm 10^{\circ} \mathrm{C}$ ) calculated by vertex average temperature of the H-beam and the maximum temperature difference as a minimum $\left(\min \left\{\Delta T_{\max }(x, y)\right\}\right)$, calculated by the vertex maximum temperature subtracting the vertex minimum temperature of the H-beam.

Above all, the CGM method evaluates the gradient of the objective functions, and then it sets up a new conjugate direction for the updated design variables with the help of a direct numerical sensitivity analysis. The initial guess for the value of each search variable was made, and in the successive steps, the conjugate-gradient coefficients and the search directions were evaluated to estimate the new search variables. The solutions obtained from the finite difference method were then used to calculate the value of the objective functions, which were further transmitted back to the optimizer for the purpose of calculating the consecutive directions. The procedure for applying this method is described in the following:

(1) Generate an initial guess for five design variables $\left(x_{1}, x_{2}, x_{3}, x_{4}, x_{5}\right)$ : the heat transfer coefficients $\left(h_{1}, h_{2}, h_{3}, h_{4}, h_{5}\right)$. 
(2) Adopt the finite difference method to predict the temperature fields $(T(x, y))$ associated with the last $\left(h_{1}, h_{2}, h_{3}, h_{4}, h_{5}\right)$, and then calculate the objective functions $J_{1 \mathrm{obj}}\left(h_{1}, h_{2}, h_{3}, h_{4}, h_{5}\right)$ and $J_{2 \mathrm{obj}}\left(h_{1}, h_{2}, h_{3}\right.$, $\left.h_{4}, h_{5}\right)$.

(3) When the value of $J_{1 \mathrm{obj}}\left(h_{1}, h_{2}, h_{3}, h_{4}, h_{5}\right)$ reaches the object range and $J_{2 \mathrm{obj}}\left(h_{1}, h_{2}, h_{3}, h_{4}, h_{5}\right)$ reaches the minimum, the optimization process is terminated. Otherwise, proceed to step (4).

(4) Determine the gradient functions, $\left(\partial J_{1 \mathrm{obj}} / \partial x_{i}\right)^{(m)}$ and $\left(\partial J_{2 \mathrm{obj}} / \partial x_{i}\right)^{(m)}(i=1,2,3,4,5)$, by applying a small perturbation $\left(\Delta x_{1}, \Delta x_{2}, \Delta x_{3}, \Delta x_{4}, \Delta x_{5}\right)$ to each value of $\left(x_{1}, x_{2}, x_{3}, x_{4}, x_{5}\right)$, and calculate the corresponding change in objective functions $J_{1 \mathrm{obj}}\left(h_{1}, h_{2}, h_{3}, h_{4}, h_{5}\right)$ and $J_{2 o b j}\left(h_{1}, h_{2}, h_{3}, h_{4}, h_{5}\right)$. Then the gradient functions with respect to each value of the design variables $\left(x_{1}, x_{2}, x_{3}, x_{4}, x_{5}\right)$ can be calculated by the direct numerical differentiation as

$$
\begin{aligned}
& \frac{\partial J_{1 \mathrm{obj}}}{\partial x_{1}}=\frac{\Delta J_{1 \mathrm{obj}}}{\Delta x_{1}}, \\
& \frac{\partial J_{1 \mathrm{obj}}}{\partial x_{2}}=\frac{\Delta J_{1 \mathrm{obj}}}{\Delta x_{2}}, \\
& \frac{\partial J_{1 \mathrm{obj}}}{\partial x_{3}}=\frac{\Delta J_{1 \mathrm{obj}}}{\Delta x_{3}}, \\
& \frac{\partial J_{1 \mathrm{obj}}}{\partial x_{4}}=\frac{\Delta J_{1 \mathrm{obj}}}{\Delta x_{4}}, \\
& \frac{\partial J_{1 \mathrm{obj}}}{\partial x_{5}}=\frac{\Delta J_{1 \mathrm{obj}}}{\Delta x_{5}} \\
& \frac{\partial J_{2 \mathrm{obj}}}{\partial x_{1}}=\frac{\Delta J_{2 \mathrm{obj}}}{\Delta x_{1}}, \\
& \frac{\partial J_{2 \mathrm{obj}}}{\partial x_{2}}=\frac{\Delta J_{2 \mathrm{obj}}}{\Delta x_{2}}, \\
& \frac{\partial J_{2 \mathrm{obj}}}{\partial x_{3}}=\frac{\Delta J_{2 \mathrm{obj}}}{\Delta x_{3}}, \\
& \frac{\partial J_{2 \mathrm{obj}}}{\partial x_{4}}=\frac{\Delta J_{2 \mathrm{obj}}}{\Delta x_{4}}, \\
& \frac{\Delta J_{2 \mathrm{obj}}}{\Delta x_{5}} .
\end{aligned}
$$

(5) Calculate the conjugate-gradient coefficients, $\gamma^{(m)}$, and the search directions, $\xi_{1}^{(m+1)}, \xi_{2}^{(m+1)}, \xi_{3}^{(m+1)}$, $\xi_{4}^{(m+1)}, \xi_{5}^{(m+1)}$, for the search variables. For the first step with $k=1, \gamma^{(1)}=0$.

$$
\begin{aligned}
\gamma^{(m)} & =\left[\frac{\sum_{n}^{2}\left(\partial J_{\mathrm{obj}}^{(m)} / \partial x_{n}\right)}{\sum_{n}^{2}\left(\partial J_{\mathrm{obj}}^{(m-1)} / \partial x_{n}\right)}\right]^{2}, n=1,2,3,4,5, \\
\xi_{1}^{(m+1)} & =\frac{\partial J_{\mathrm{obj}}^{(m)}}{\partial x_{1}}+\gamma^{(m)} \xi_{1}^{(m)}, \\
\xi_{2}^{(m+1)} & =\frac{\partial J_{\mathrm{obj}}^{(m)}}{\partial x_{2}}+\gamma^{(m)} \xi_{2}^{(m)}, \\
\xi_{3}^{(m+1)} & =\frac{\partial J_{\mathrm{obj}}^{(m)}}{\partial x_{3}}+\gamma^{(m)} \xi_{3}^{(m)}, \\
\xi_{4}^{(m+1)} & =\frac{\partial J_{\mathrm{obj}}^{(m)}}{\partial x_{4}}+\gamma^{(m)} \xi_{4}^{(m)}, \\
\xi_{5}^{(m+1)} & =\frac{\partial J_{\mathrm{obj}}^{(m)}}{\partial x_{5}}+\gamma^{(m)} \xi_{5}^{(m)} .
\end{aligned}
$$

(6) Assign values to the coefficients in a descending direction $\left(\beta_{1}, \beta_{2}, \beta_{3}, \beta_{4}, \beta_{5}\right)$ for all values of the design variables $\left(x_{1}, x_{2}, x_{3}, x_{4}, x_{5}\right)$. Specifically, these values are chosen with a trial and error process. In general, the coefficients in the descending direction $\left(\beta_{1}, \beta_{2}, \beta_{3}, \beta_{4}, \beta_{5}\right)$ range from 1 to 50 .

(7) Update the design variables with

$$
\begin{aligned}
& x_{1}^{(m+1)}=x_{1}^{(m)}+\beta_{1} \xi_{1}^{(m)}, \\
& x_{2}^{(m+1)}=x_{2}^{(m)}+\beta_{2} \xi_{2}^{(m)}, \\
& x_{3}^{(m+1)}=x_{3}^{(m)}+\beta_{3} \xi_{3}^{(m)}, \\
& x_{4}^{(m+1)}=x_{4}^{(m)}+\beta_{4} \xi_{4}^{(m)}, \\
& x_{5}^{(m+1)}=x_{5}^{(m)}+\beta_{5} \xi_{5}^{(m)} .
\end{aligned}
$$

A flowchart of the CGM optimization process is plotted as Figure 5.

\section{Result and Discussion}

In order to examine the validity of the results of the CGM method, two initial guess values were used to search for the optimal heat transfer coefficient distributions of the $\mathrm{H}$ beams for three cases, and they all obtained approximately the same result. Based on the optimal heat transfer coefficient distributions using CGM method, the temperature field and the residual stress of the $\mathrm{H}$-beam were calculated to compare with the constant heat transfer coefficient results. Taking into account the operability in the cooling process, the area of the up surface of the flange is small and not in the water cooling range; therefore, the heat transfer coefficient $h_{5}$ is a significantly smaller value than $h_{1}$ to $h_{4}$.

Figure 6 shows the final average temperature and the maximum temperature difference search path, where the initial guess value 1 was $h_{1}=h_{2}=h_{3}=h_{4}=1600\left(\mathrm{~W} / \mathrm{m}^{2} \mathrm{~K}\right)$, 


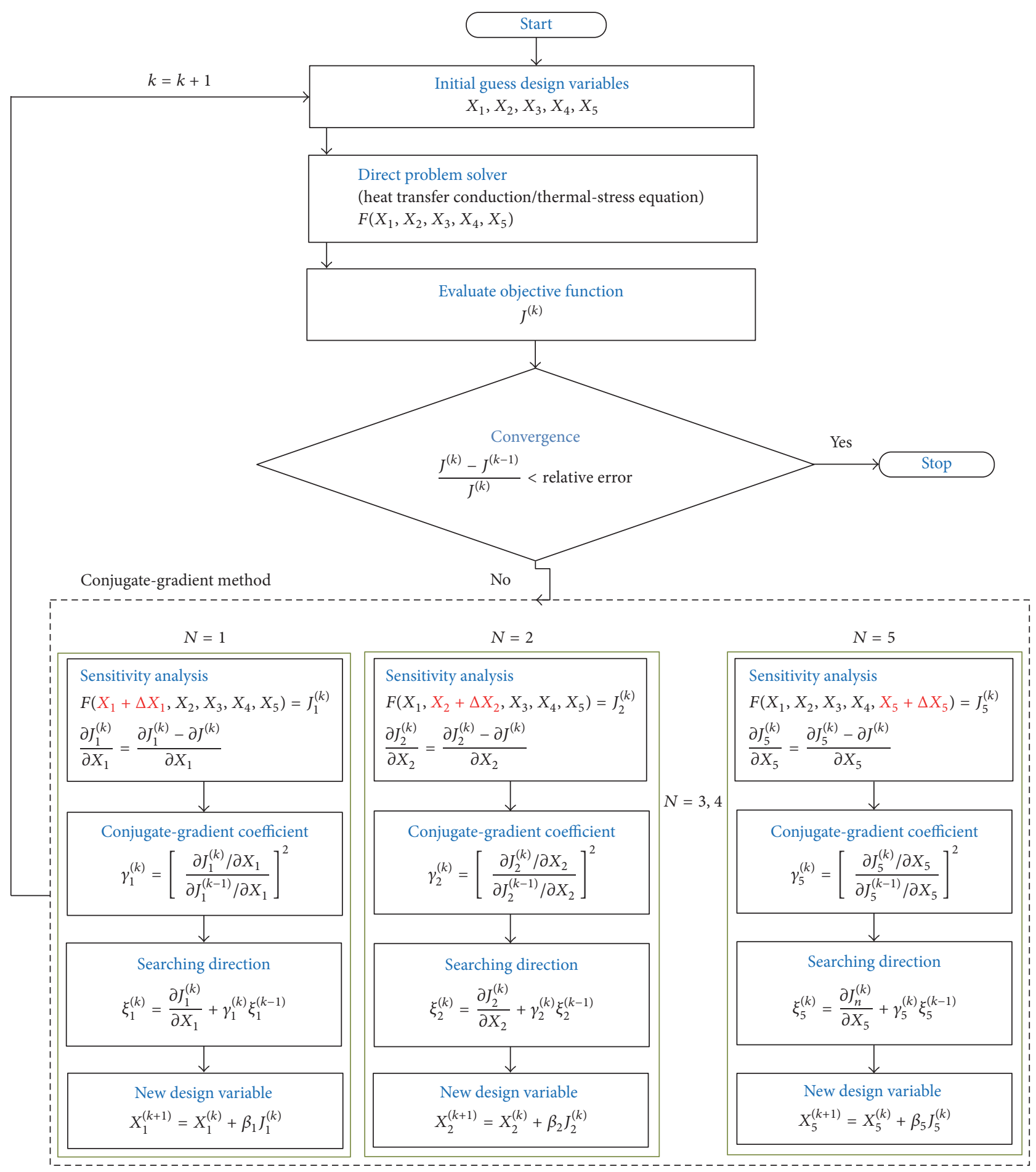

$X$ : design variables (heat transfer coefficient $h$ )

$F\left(X_{1}, X_{2}, X_{3}, X_{4}, X_{5}\right)$ : functions

$J^{(k)}$ : objective functions (the average temperature and the temperature difference, $T_{\text {ave }} \pm \Delta T, \min \Delta T_{\max }$ )

FIgURE 5: A flowchart of the CGM optimization process. 
$h_{5}=160\left(\mathrm{~W} / \mathrm{m}^{2} \mathrm{~K}\right)$ and the initial guess value 2 was $h_{1}=$ $h_{2}=h_{3}=h_{4}=1200\left(\mathrm{~W} / \mathrm{m}^{2} \mathrm{~K}\right), h_{5}=120\left(\mathrm{~W} / \mathrm{m}^{2} \mathrm{~K}\right)$ for Case 1. The initial guess values for heat transfer coefficients $h_{1}=h_{2}=h_{3}=h_{4}=1600 \mathrm{~W} / \mathrm{m}^{2} \mathrm{~K}$ in water are estimated from the water jet heat transfer coefficient correlations by Wendelstorf et al. [22], while the $h_{5}=160 \mathrm{~W} / \mathrm{m}^{2} \mathrm{~K}$ in air is estimated from the combined natural and radiation heat transfer theory [23]. The search trend of the final average temperature for these two initial guess values was close to the objective value step by step and were within the error range. The search trend for the temperature difference for the two initial guess values was obtained by searching for the lowest value step by step with the final average temperature in the range of the objective value until the temperature difference variable was stable. The different search steps were obtained for different initial guess values, but they all obtained almost the same result, where the resultant deviation for the two initial values was below $1^{\circ} \mathrm{C}$. It is apparent that Case 2 and Case 3 both had the same search path as that of Case 1. The initial guess value 1 was $h_{1}=h_{2}=h_{3}=h_{4}=1500\left(\mathrm{~W} / \mathrm{m}^{2} \mathrm{~K}\right)$, $h_{5}=150\left(\mathrm{~W} / \mathrm{m}^{2} \mathrm{~K}\right)$ and the initial guess value 2 was $h_{1}=h_{2}=$ $h_{3}=h_{4}=1000\left(\mathrm{~W} / \mathrm{m}^{2} \mathrm{~K}\right), h_{5}=100\left(\mathrm{~W} / \mathrm{m}^{2} \mathrm{~K}\right)$ for Case 2 ; the initial guess value 1 was $h_{1}=h_{2}=h_{3}=h_{4}=1200\left(\mathrm{~W} / \mathrm{m}^{2} \mathrm{~K}\right)$, $h_{5}=120\left(\mathrm{~W} / \mathrm{m}^{2} \mathrm{~K}\right)$, and the initial guess value 2 was $h_{1}=$ $h_{2}=h_{3}=h_{4}=800\left(\mathrm{~W} / \mathrm{m}^{2} \mathrm{~K}\right), h_{5}=80\left(\mathrm{~W} / \mathrm{m}^{2} \mathrm{~K}\right)$ for Case 3 , respectively. For the three cases, there were different search steps for the difference cases and initial guess values, where the search steps were simply related to the initial guess value and the search step size.

Tables 1-3 list the different distributions of the heat transfer coefficients for an example with ten points in the optimization search process, where the final average temperatures were all in a range of $540^{\circ} \mathrm{C}$ to $560^{\circ} \mathrm{C}$, but the temperature difference decreased from $201^{\circ} \mathrm{C}$ to $144^{\circ} \mathrm{C}$, from $204^{\circ} \mathrm{C}$ to $130^{\circ} \mathrm{C}$, and from $179^{\circ} \mathrm{C}$ to $104^{\circ} \mathrm{C}$ for Case 1 to Case 3, respectively. The optimization distribution of the heat transfer coefficients is the tenth point in Tables 1-3. For Case 1, the optimization distribution of heat transfer coefficients $h_{1}$ to $h_{5}$ is $1227,1745,1732,1479$, and $101\left(\mathrm{~W} / \mathrm{m}^{2} \mathrm{~K}\right)$, where the average temperature is $560^{\circ} \mathrm{C}$, and the temperature difference is $144^{\circ} \mathrm{C}$. For Case 2, the optimization distribution of the heat transfer coefficients $h_{1}$ to $h_{5}$ is $1091,1705,1666$, 1445 , and $37\left(\mathrm{~W} / \mathrm{m}^{2} \mathrm{~K}\right)$, where the average temperature is $560^{\circ} \mathrm{C}$, and the temperature difference is $130^{\circ} \mathrm{C}$. For Case 3 , the optimization distribution of heat transfer coefficients $h_{1}$ to $h_{5}$ is $913,1579,1556,1166$, and $225\left(\mathrm{~W} / \mathrm{m}^{2} \mathrm{~K}\right)$, where the final average temperature is $560^{\circ} \mathrm{C}$, and the temperature difference is $104^{\circ} \mathrm{C}$.

Figure 7 shows that the variation of the average temperature in the different parts of the beam and that the maximum temperature difference with time for the three cases under two heat boundary conditions satisfied the average temperature of $\mathrm{H}$-beams in the range of $540 \sim 560^{\circ} \mathrm{C}$. For Case 1 , when the heat transfer coefficients were constant $\left(h_{1}=h_{2}=h_{3}=\right.$ $\left.h_{4}=1500\left(\mathrm{~W} / \mathrm{m}^{2} \mathrm{~K}\right), h_{5}=150\left(\mathrm{~W} / \mathrm{m}^{2} \mathrm{~K}\right)\right)$, the different parts had different trends in variation. For the web, the cooling rate was very fast at first and then gradually slowed with the decrease of the web surface temperature, and when the time was over 12 seconds, the cooling rate became as fast as it was originally. In the case of the flange, the cooling rate was slower than that of the web, where the cooling rate went from fast to slow. In the case of the fillet, the cooling rate was the slowest and exhibited the same variable trends as that of the flange. The maximum temperature difference increased initially in the first 6 seconds and then decreased slightly until the maximum temperature difference was $201^{\circ} \mathrm{C}$ at 15 seconds. When the heat transfer coefficients were optimized $\left(h_{1}=\right.$ $1227\left(\mathrm{~W} / \mathrm{m}^{2} \mathrm{~K}\right), h_{2}=1745\left(\mathrm{~W} / \mathrm{m}^{2} \mathrm{~K}\right), h_{3}=1732\left(\mathrm{~W} / \mathrm{m}^{2} \mathrm{~K}\right)$, $h_{4}=1479\left(\mathrm{~W} / \mathrm{m}^{2} \mathrm{~K}\right)$, and $\left.h_{5}=101\left(\mathrm{~W} / \mathrm{m}^{2} \mathrm{~K}\right)\right)$, the variation of the average temperature with time in the different parts exhibited the same trends compared with the results of the constant heat transfer coefficients, except the fillet cooling rate was slightly larger than that of the constant heat transfer coefficients; the flange cooling rate was slightly less than that of the constant heat transfer coefficients; the web cooling rate was obviously slower than that of the constant heat transfer coefficients, and the cooling rate of the web went from fast to slow. The temperature difference for the optimal heat transfer coefficients increased initially and then decreased until the maximum temperature difference was $144^{\circ} \mathrm{C}$ at 15 seconds, and the peak of the temperature difference was controlled at 6 seconds. For Case 2 and Case 3, the constant heat transfer coefficients were $h_{1}=h_{2}=h_{3}=h_{4}=$ $1400\left(\mathrm{~W} / \mathrm{m}^{2} \mathrm{~K}\right), h_{5}=140\left(\mathrm{~W} / \mathrm{m}^{2} \mathrm{~K}\right)$, and $h_{1}=h_{2}=h_{3}=$ $h_{4}=1200\left(\mathrm{~W} / \mathrm{m}^{2} \mathrm{~K}\right), h_{5}=120\left(\mathrm{~W} / \mathrm{m}^{2} \mathrm{~K}\right)$, and the optimal heat transfer coefficients were $h_{1}=1091\left(\mathrm{~W} / \mathrm{m}^{2} \mathrm{~K}\right), h_{2}=$ $1705\left(\mathrm{~W} / \mathrm{m}^{2} \mathrm{~K}\right), h_{3}=1666\left(\mathrm{~W} / \mathrm{m}^{2} \mathrm{~K}\right), h_{4}=1444\left(\mathrm{~W} / \mathrm{m}^{2} \mathrm{~K}\right)$, $h_{5}=37\left(\mathrm{~W} / \mathrm{m}^{2} \mathrm{~K}\right)$, and $h_{1}=913\left(\mathrm{~W} / \mathrm{m}^{2} \mathrm{~K}\right), h_{2}=$ $1579\left(\mathrm{~W} / \mathrm{m}^{2} \mathrm{~K}\right), h_{3}=1556\left(\mathrm{~W} / \mathrm{m}^{2} \mathrm{~K}\right), h_{4}=1166\left(\mathrm{~W} / \mathrm{m}^{2} \mathrm{~K}\right)$, and $h_{5}=225\left(\mathrm{~W} / \mathrm{m}^{2} \mathrm{~K}\right)$, respectively. The variation of the average temperature with time exhibited the same trends as those found for Case 1, regardless of whether it was determined with constant heat transfer coefficients or optimal heat transfer coefficients. The cooling rates of Case 2 among the web, flange, and fillet were closer than in Case 1, and Case 3 was the closest because of the physical dimensions. The temperature difference for the constant heat transfer coefficients reached a peak at 6.5 seconds and 7 seconds for Case 2 and Case 3 and then slowly decreased until the temperature differences were $204^{\circ} \mathrm{C}$ and $180^{\circ} \mathrm{C}$ at 15 seconds, respectively. The maximum temperature difference of the optimal heat transfer coefficients reached a peak at 4 seconds and at 3 seconds for Case 2 and Case 3 and then slowly decreased to $130^{\circ} \mathrm{C}$ and $104^{\circ} \mathrm{C}$ at 15 seconds, respectively.

Figure 8 displays the temperature field for three cases with constant heat transfer coefficients and optimal heat transfer coefficients at 15 seconds. For Case 1, the temperature ranged from $667^{\circ} \mathrm{C}$ to $466^{\circ} \mathrm{C}$ with the constant heat transfer coefficients, and the temperature ranged from $654^{\circ} \mathrm{C}$ to $510^{\circ} \mathrm{C}$ with the optimal heat transfer coefficients. For Case 2, the temperature ranged from $658^{\circ} \mathrm{C}$ to $454^{\circ} \mathrm{C}$ with the constant heat transfer coefficients, and the temperature ranged from $639^{\circ} \mathrm{C}$ to $509^{\circ} \mathrm{C}$ with the optimal heat transfer coefficients. For Case 3 , the temperature ranged from $646^{\circ} \mathrm{C}$ to $466^{\circ} \mathrm{C}$ with the constant heat transfer coefficients, and the temperature ranged from $618^{\circ} \mathrm{C}$ to $514^{\circ} \mathrm{C}$ with the optimal heat transfer coefficients; the surface maximum temperature difference 

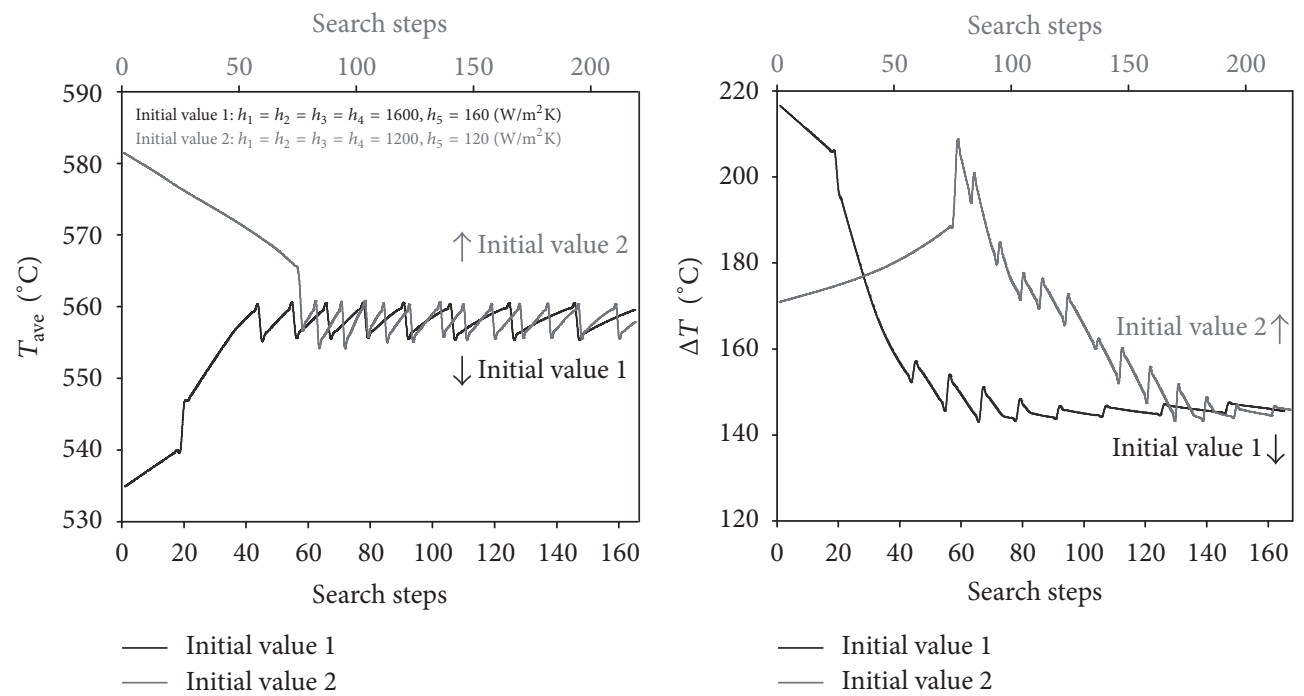

(a) Case 1
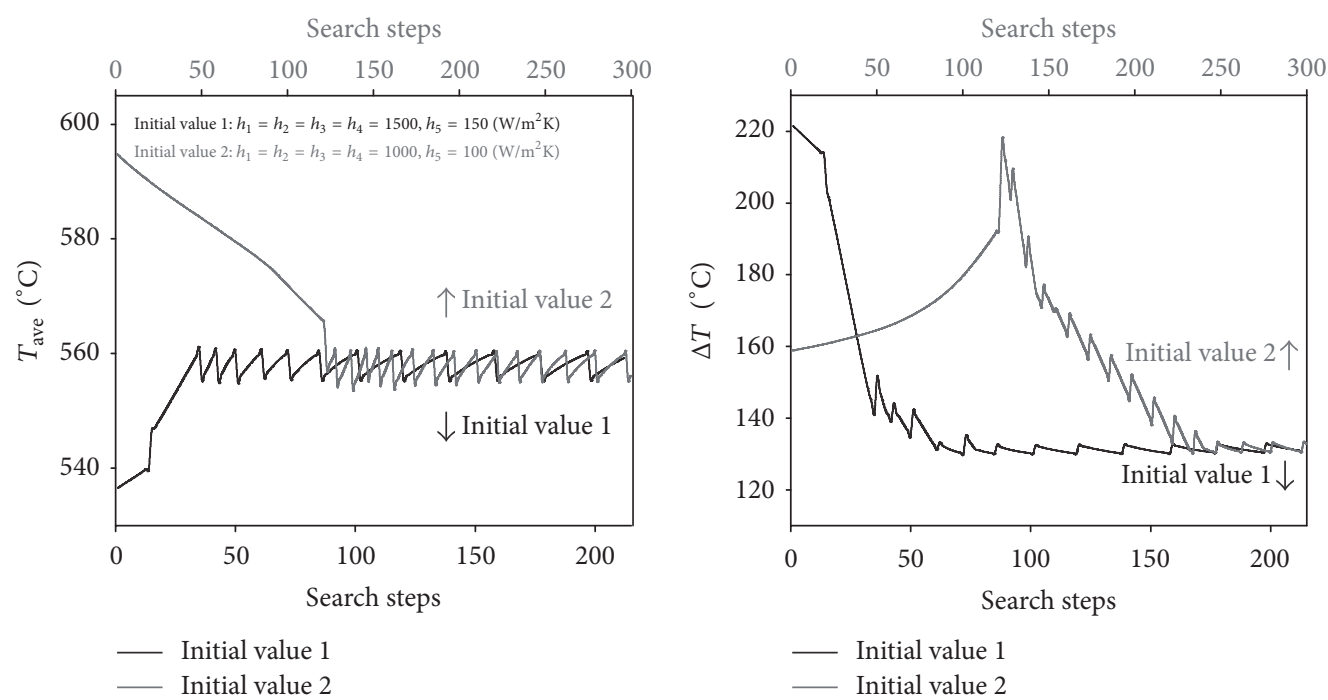

(b) Case 2
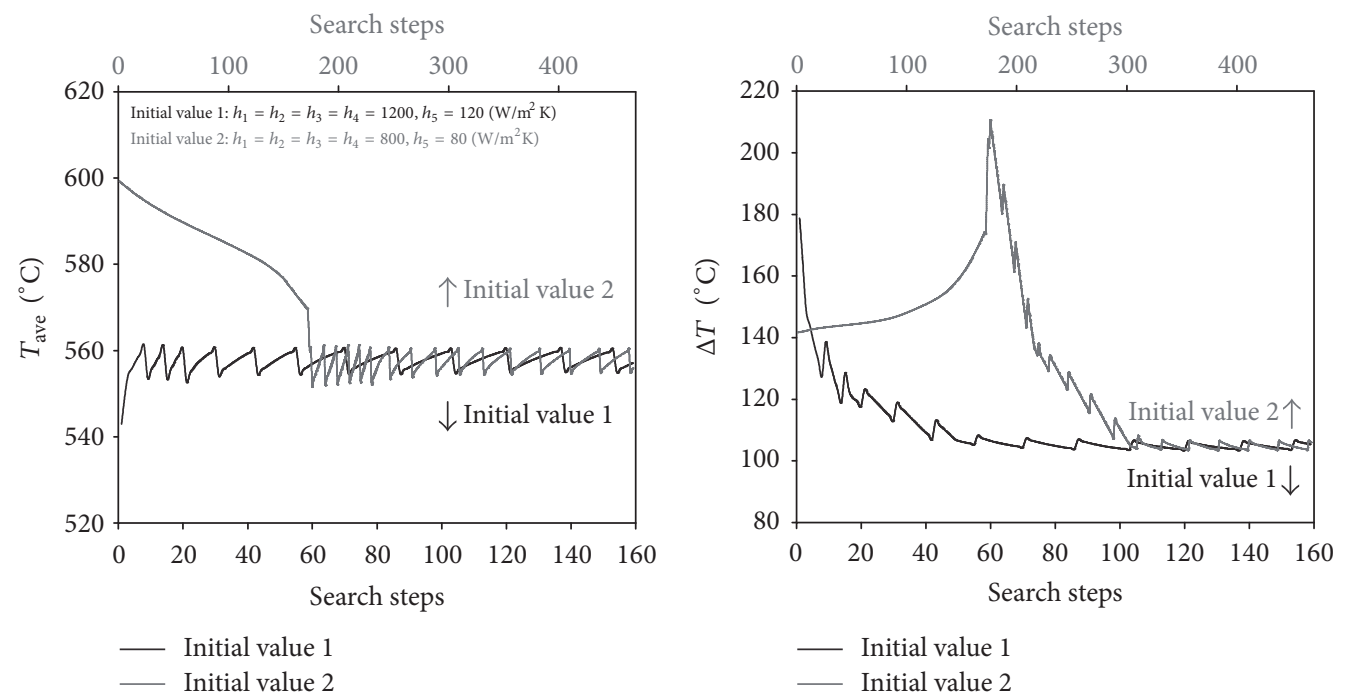

(c) Case 3

Figure 6: The search path with the different initial values for the three cases. 

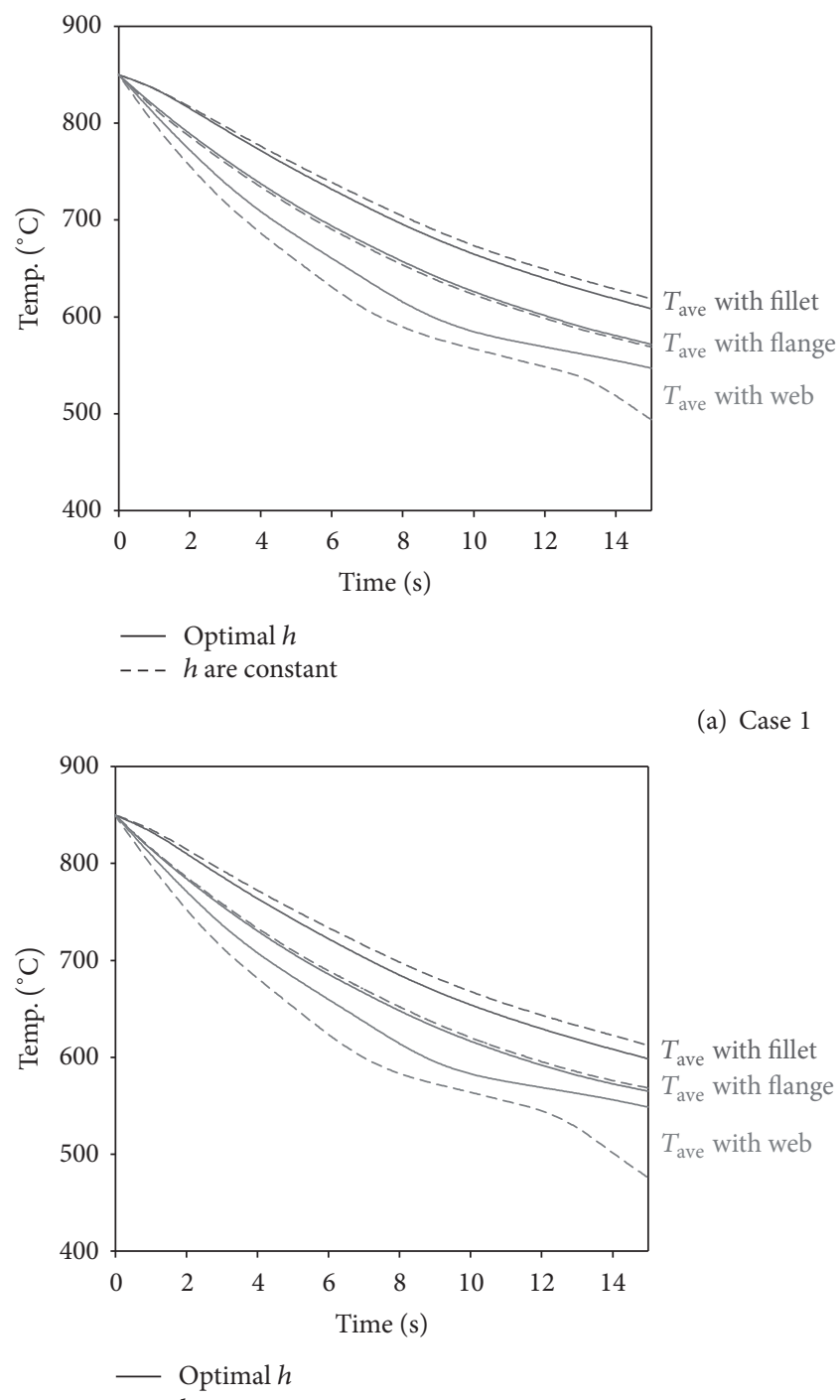

- - $h$ are constant

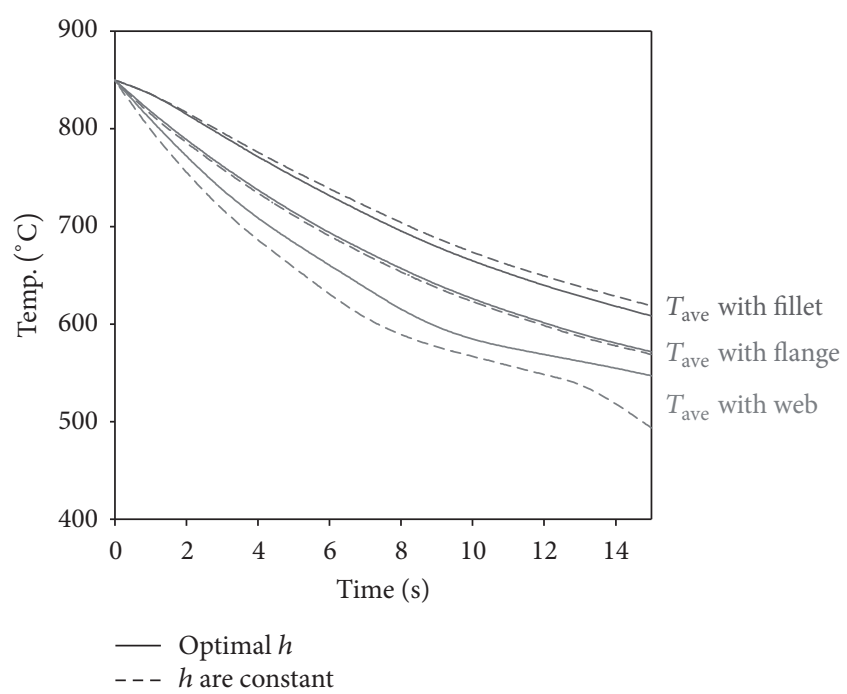

(a) Case 1
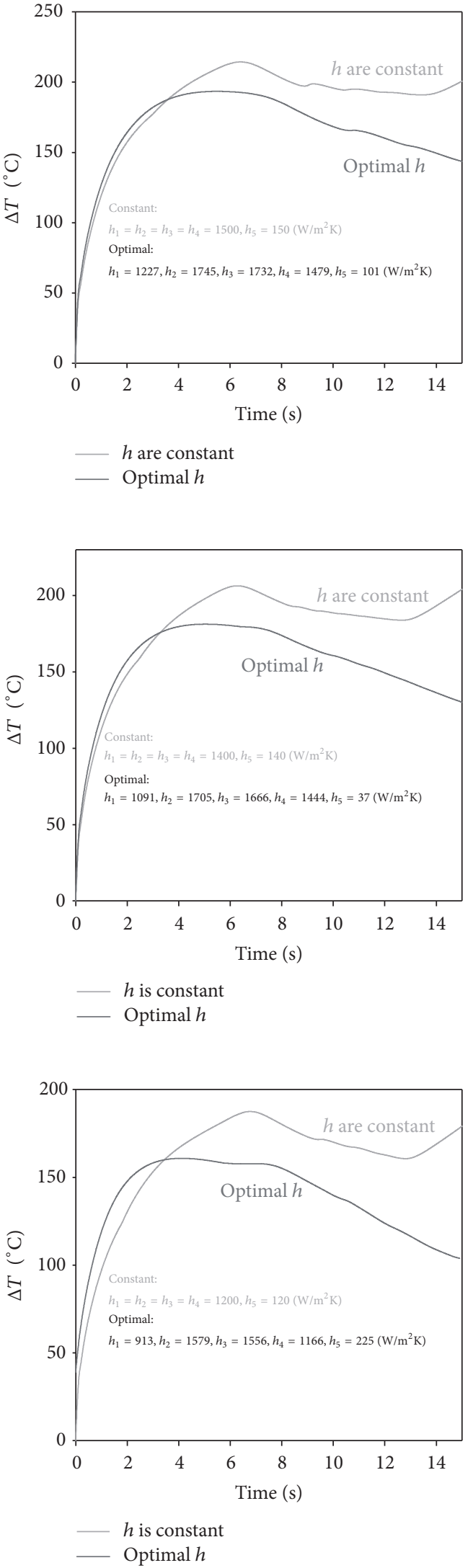

(c) Case 3

FIGURE 7: The temperature in different parts and the temperature difference variable with time. 


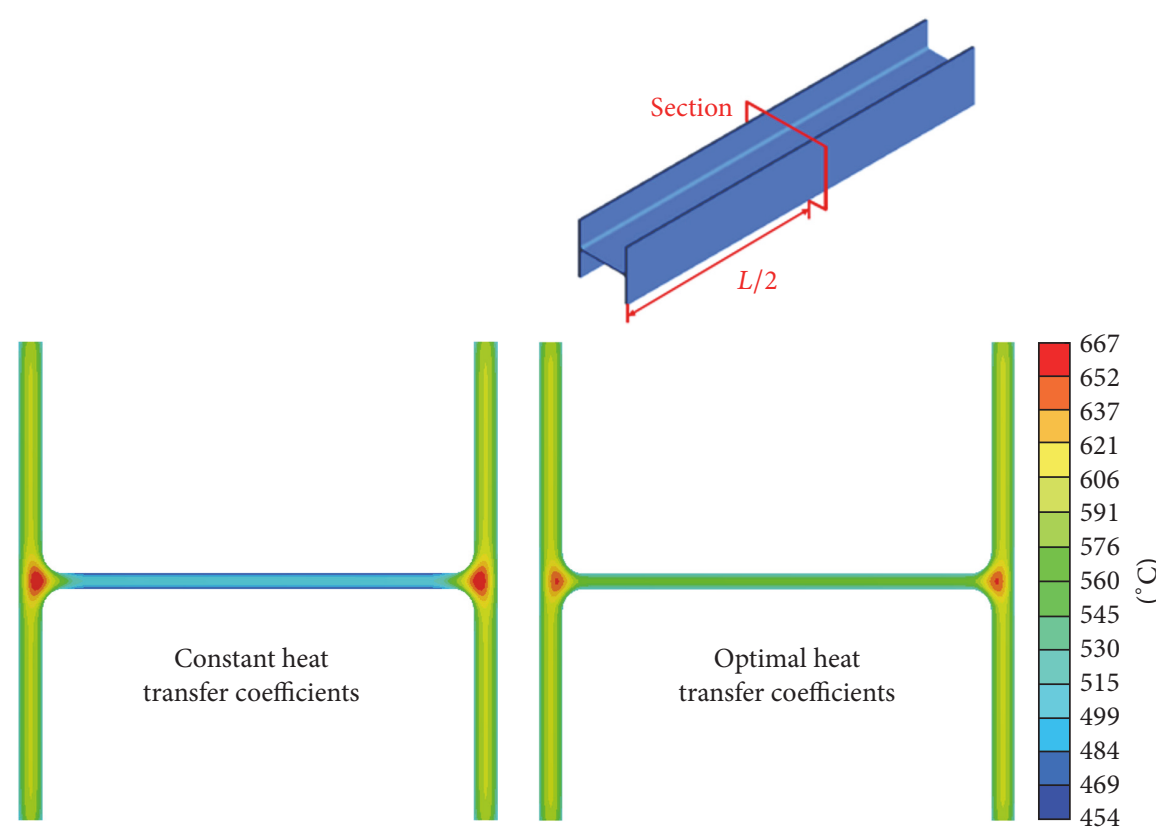

(a) Case 1
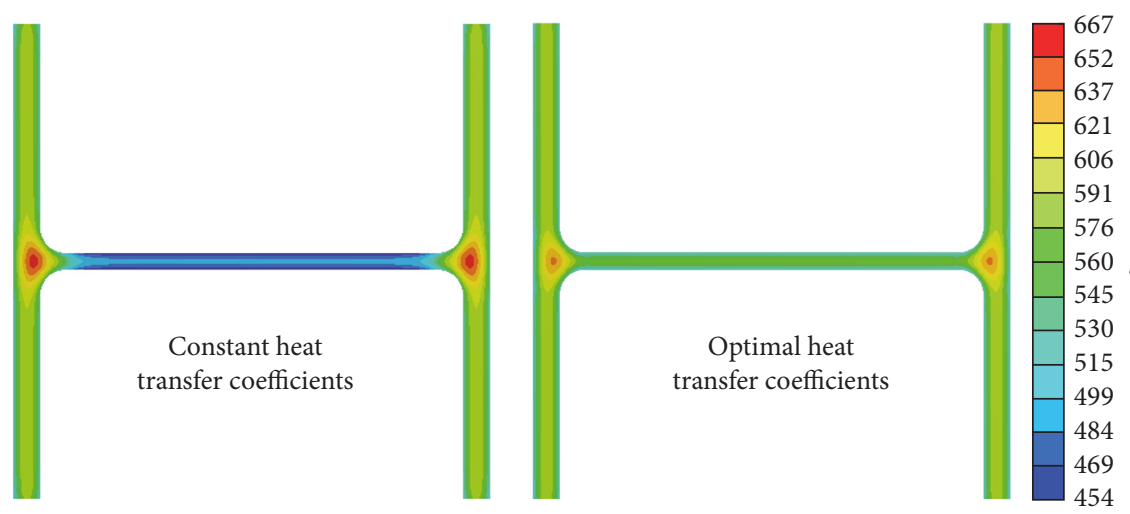

(b) Case 2
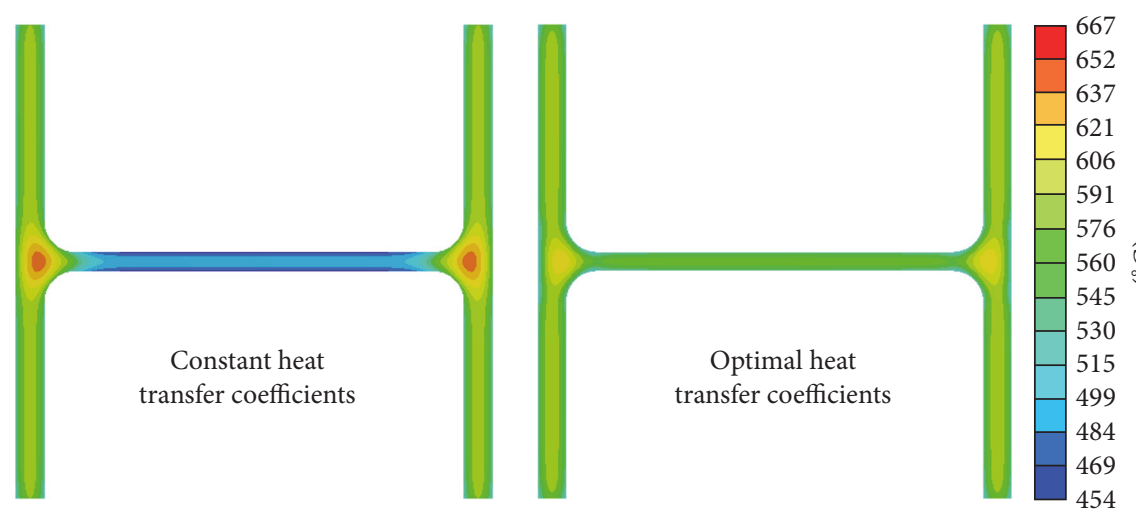

(c) Case 3

FIGURE 8: The distribution of temperature with the different heat transfer coefficients at 15 seconds in a section of the $\mathrm{H}$-beams.

is decreased by $60 \sim 80^{\circ} \mathrm{C}$ for three cases. For the three cases, the temperature field for the optimal heat transfer coefficients was more uniform than for the temperature field of the constant heat transfer coefficients. Also, from
Case 1 to Case 3, the sizes became gradually smaller, so the temperature differences were also smaller.

Figure 9 and Table 4 display the residual stress distribution at the web for three cases with constant heat transfer 
TABLE 1: The optimization search of $h_{1}-h_{5}$ distribution for Case 1 (e.g., with ten points).

\begin{tabular}{|c|c|c|c|c|c|c|c|}
\hline Number & $\begin{array}{c}h_{1} \\
\mathrm{~W} / \mathrm{m}^{2} \mathrm{~K}\end{array}$ & $\begin{array}{c}h_{2} \\
\mathrm{~W} / \mathrm{m}^{2} \mathrm{~K}\end{array}$ & $\begin{array}{c}h_{3} \\
\mathrm{~W} / \mathrm{m}^{2} \mathrm{~K}\end{array}$ & $\begin{array}{c}h_{4} \\
\mathrm{~W} / \mathrm{m}^{2} \mathrm{~K}\end{array}$ & $\begin{array}{c}h_{5} \\
\mathrm{~W} / \mathrm{m}^{2} \mathrm{~K}\end{array}$ & $\begin{array}{c}T_{\text {ave }} \\
{ }^{\circ} \mathrm{C}\end{array}$ & $\begin{array}{l}\Delta T \\
{ }^{\circ} \mathrm{C} \\
\end{array}$ \\
\hline (1) (constant) & 1500 & 1500 & 1500 & 1500 & 150 & 550 & 201 \\
\hline$(2)$ & 1546 & 1595 & 1596 & 1557 & 157 & 540 & 205 \\
\hline (3) & 1485 & 1547 & 1548 & 1507 & 107 & 546 & 195 \\
\hline$(4)$ & 1419 & 1556 & 1555 & 1508 & 107 & 550 & 180 \\
\hline$(5)$ & 1335 & 1576 & 1427 & 1415 & 167 & 555 & 176 \\
\hline$(6)$ & 1309 & 1565 & 1497 & 1482 & 163 & 556 & 170 \\
\hline (7) & 1316 & 1572 & 1568 & 1507 & 106 & 557 & 160 \\
\hline (8) & 1264 & 1642 & 1635 & 1504 & 111 & 558 & 150 \\
\hline (9) & 1240 & 1702 & 1695 & 1490 & 105 & 559 & 145 \\
\hline (10) (optimization) & 1227 & 1745 & 1732 & 1479 & 101 & 560 & 144 \\
\hline
\end{tabular}

TABLE 2: The optimization search of $h_{1}-h_{5}$ distribution for Case 2 (e.g., with ten points).

\begin{tabular}{|c|c|c|c|c|c|c|c|}
\hline Number & $\begin{array}{c}h_{1} \\
\mathrm{~W} / \mathrm{m}^{2} \mathrm{~K}\end{array}$ & $\begin{array}{c}h_{2} \\
\mathrm{~W} / \mathrm{m}^{2} \mathrm{~K}\end{array}$ & $\begin{array}{c}h_{3} \\
\mathrm{~W} / \mathrm{m}^{2} \mathrm{~K}\end{array}$ & $\begin{array}{c}h_{4} \\
\mathrm{~W} / \mathrm{m}^{2} \mathrm{~K}\end{array}$ & $\begin{array}{c}h_{5} \\
\mathrm{~W} / \mathrm{m}^{2} \mathrm{~K}\end{array}$ & $\begin{array}{c}T_{\text {ave }} \\
{ }^{\circ} \mathrm{C}\end{array}$ & $\begin{array}{l}\Delta T \\
{ }^{\circ} \mathrm{C} \\
\end{array}$ \\
\hline (1) (constant) & 1400 & 1400 & 1400 & 1400 & 140 & 548 & 204 \\
\hline (2) & 1340 & 1449 & 1450 & 1419 & 100 & 548 & 198 \\
\hline (3) & 1365 & 1453 & 1452 & 1420 & 99 & 549 & 192 \\
\hline (4) & 1315 & 1460 & 1458 & 1421 & 98 & 551 & 178 \\
\hline (5) & 1289 & 1464 & 1461 & 1421 & 96 & 553 & 172 \\
\hline (6) & 1213 & 1482 & 1475 & 1465 & 92 & 555 & 151 \\
\hline (7) & 1181 & 1545 & 1485 & 1486 & 67 & 556 & 142 \\
\hline (8) & 1133 & 1610 & 1550 & 1477 & 64 & 558 & 136 \\
\hline (9) & 1109 & 1610 & 1555 & 1456 & 44 & 559 & 132 \\
\hline (10) (optimization) & 1091 & 1705 & 1666 & 1445 & 37 & 560 & 130 \\
\hline
\end{tabular}

TABLE 3: The optimization search of $h_{1}-h_{5}$ distribution for Case 3 (e.g., with ten points).

\begin{tabular}{|c|c|c|c|c|c|c|c|}
\hline Number & $\begin{array}{c}h_{1} \\
\mathrm{~W} / \mathrm{m}^{2} \mathrm{~K}\end{array}$ & $\begin{array}{c}h_{2} \\
\mathrm{~W} / \mathrm{m}^{2} \mathrm{~K}\end{array}$ & $\begin{array}{c}h_{3} \\
\mathrm{~W} / \mathrm{m}^{2} \mathrm{~K}\end{array}$ & $\begin{array}{c}h_{4} \\
\mathrm{~W} / \mathrm{m}^{2} \mathrm{~K}\end{array}$ & $\begin{array}{c}h_{5} \\
\mathrm{~W} / \mathrm{m}^{2} \mathrm{~K}\end{array}$ & $\begin{array}{c}T_{\text {ave }} \\
{ }^{\circ} \mathrm{C}\end{array}$ & $\begin{array}{l}\Delta T \\
{ }^{\circ} \mathrm{C}\end{array}$ \\
\hline (1) (constant) & 1200 & 1200 & 1200 & 1200 & 120 & 543 & 179 \\
\hline$(2)$ & 1213 & 945 & 934 & 1087 & 101 & 552 & 210 \\
\hline (3) & 1168 & 1013 & 1000 & 1140 & 151 & 553 & 189 \\
\hline$(4)$ & 1121 & 1081 & 1065 & 1192 & 201 & 553 & 168 \\
\hline (5) & 1074 & 1148 & 1130 & 1243 & 201 & 555 & 147 \\
\hline (6) & 1038 & 1213 & 1191 & 1267 & 182 & 556 & 133 \\
\hline$(7)$ & 1017 & 1278 & 1254 & 1280 & 204 & 556 & 131 \\
\hline (8) & 991 & 1353 & 1323 & 1265 & 203 & 557 & 123 \\
\hline (9) & 959 & 1435 & 1398 & 1223 & 181 & 559 & 111 \\
\hline (10) (optimization) & 913 & 1579 & 1556 & 1166 & 225 & 560 & 104 \\
\hline
\end{tabular}

coefficients and optimal heat transfer coefficients based on the analysis of the temperature field. From Figure 9, the flange and the fillet of the residual stress are tensor in nature; the web of the residual stress is compressive in nature, with the maximum compressive stress occurring at the junction of the web and the fillet. For Case 1, the residual stress in the web is in the range of $-125 \mathrm{MPa}$ to $-107 \mathrm{MPa}$ with the constant heat transfer coefficients and is about $-90 \mathrm{MPa}$ with optimal heat transfer coefficients. For Case 2, the residual stress in the web is in the range of $-100 \mathrm{MPa}$ to $-80 \mathrm{MPa}$ with the constant heat transfer coefficients and is about $-60 \mathrm{MPa}$ with optimal heat transfer coefficients. For Case 3, the residual stress in the web is in the range of $-80 \mathrm{MPa}$ to $-70 \mathrm{MPa}$ with the constant heat transfer coefficients and is about $-50 \mathrm{MPa}$ with optimal heat transfer coefficients. From Table 4, it is observed that optimum heat transfer coefficients result in 


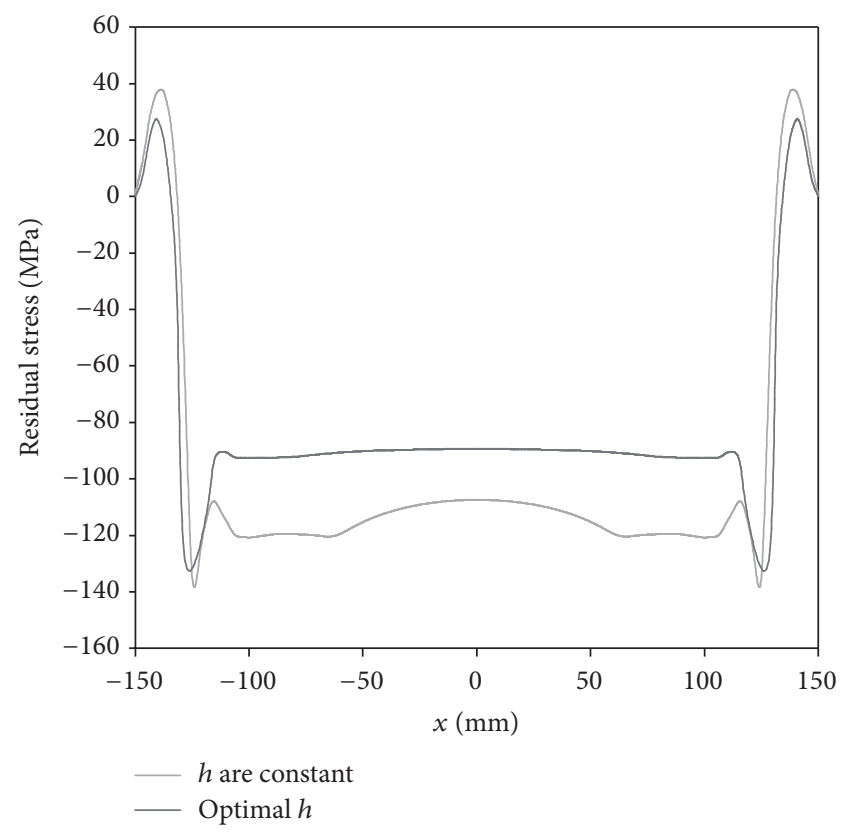

(a) Case 1

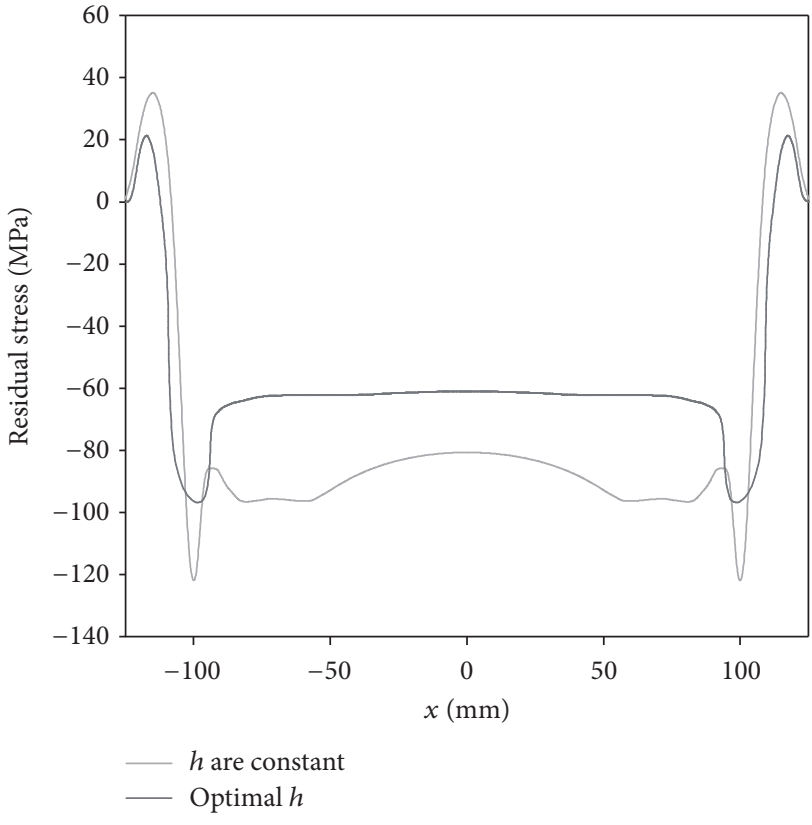

(b) Case 2

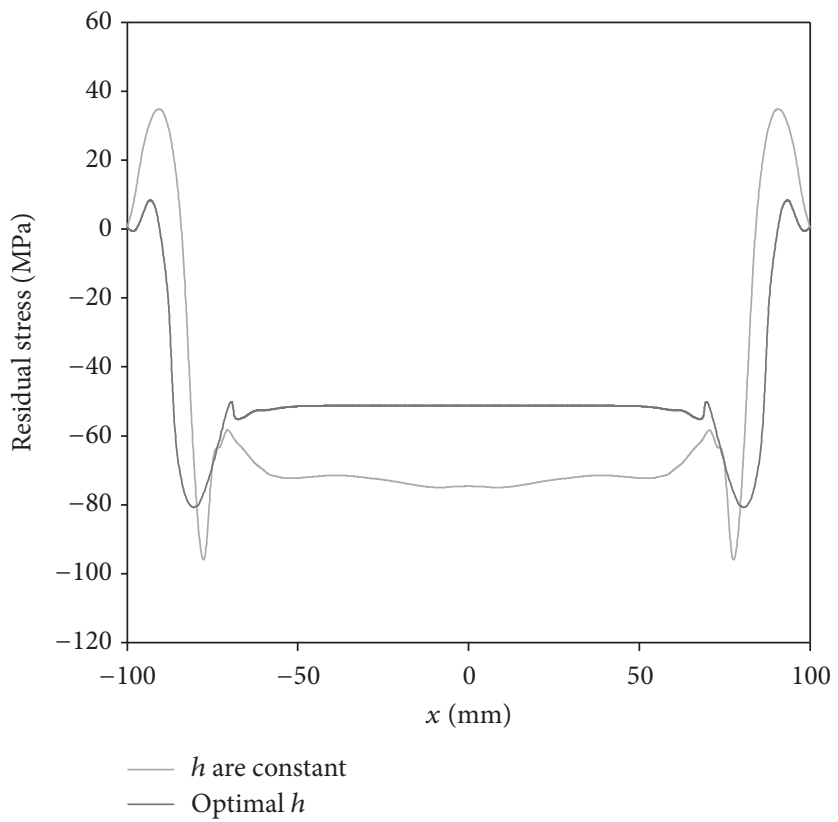

(c) Case 3

Figure 9: The residual stresses distribution at the web.

TABLE 4: A comparison of the results for the three cases.

\begin{tabular}{lcccccc}
\hline \multirow{2}{*}{ Case } & \multicolumn{2}{c}{ Case 1} & \multicolumn{2}{c}{ Case 2 } & \multicolumn{2}{c}{ Case 3 } \\
& Constant & Optimal & Constant & Optimal & Constant & Optimal \\
\hline$h_{1}\left(\mathrm{~W} / \mathrm{m}^{2} \mathrm{~K}\right)$ & 1500 & 1227 & 1400 & 1091 & 1200 \\
$h_{2}\left(\mathrm{~W} / \mathrm{m}^{2} \mathrm{~K}\right)$ & 1500 & 1745 & 1400 & 1705 & 1200 \\
$h_{3}\left(\mathrm{~W} / \mathrm{m}^{2} \mathrm{~K}\right)$ & 1500 & 1732 & 1400 & 1666 & 1200 \\
$h_{4}\left(\mathrm{~W} / \mathrm{m}^{2} \mathrm{~K}\right)$ & 1500 & 1479 & 1400 & 1445 & 1579 \\
$h_{5}\left(\mathrm{~W} / \mathrm{m}^{2} \mathrm{~K}\right)$ & 150 & 101 & 140 & 37 & 1556 \\
$\Delta T_{\max }\left({ }^{\circ} \mathrm{C}\right)$ & 201 & 144 & 204 & 130 & 120 & 180 \\
Residual stress at web $(\mathrm{MPa})$ & -114 & -91 & -89 & -62 & -73 & 104 \\
\hline
\end{tabular}


smaller differences in maximum temperature and thereby generated a lower residual stress distribution in the web across all sizes of the beams researched in this paper.

\section{Conclusions}

The conjugate-gradient method (CGM) was used here to predict the optimization heat transfer coefficient distribution of H-beams with different sizes. To this end, three 3D numerical models were analyzed to estimate the temperature field and the residual stresses field developed during the cooling process. The results from the optimal heat transfer coefficients were compared with those constant heat transfer coefficients. Based on the numerical results, the conclusion can be summarized as follows:

(1) The conjugate-gradient method (CGM) has accurately predicted the heat transfer coefficients, and the different initial guess values have resulted in very similar result. In the search process, we can get many heat transfer coefficients to satisfy the average temperature with different temperature differences, and there is a group of heat transfer coefficients that has the lowest temperature difference using the CGM optimization search method.

(2) A comparison of the constant heat transfer coefficients and the optimal heat transfer coefficients reveals obvious improvement in the predicted uniform temperature field and temperature difference with the optimal heat transfer coefficients, where the maximum temperature difference and the surface maximum temperature difference are decreased for all the cases analyzed.

(3) The cooling rate was fastest in the web, followed by the flange and the fillet.

(4) After the water cooling and the air cooling to the ambient temperature, the residual stress at the web was calculated, and a comparison of the three results for the constant heat transfer coefficients and optimal heat transfer coefficients indicates that the residual stress can be reduced by 20 40 MPa for the three cases.

\section{Nomenclature}

$B: \quad$ Flange width, $\mathrm{mm}$

$C_{p}:$ Specific heat, $\mathrm{J} \cdot \mathrm{kg}^{-1} \cdot \mathrm{K}^{-1}$

E: Young's modulus, GPa

$h$ : Heat transfer coefficient, $\mathrm{W} \cdot \mathrm{m}^{-2} \mathrm{~K}^{-1}$

$H$ : Web height, $\mathrm{mm}$

$J_{\text {obj: }}$ : Objective functions

$k$ : Thermal conductivity, $\mathrm{W} \cdot \mathrm{m}^{-1} \cdot \mathrm{K}^{-1}$

$R: \quad$ Fillet radius, $\mathrm{mm}$

$s_{i j}$ : The component of deviatoric stresses, $\mathrm{MPa}$

T: Temperature, ${ }^{\circ} \mathrm{C}$

$t_{1}$ : Web thickness, $\mathrm{mm}$

$t_{2}$ : Flange thickness, $\mathrm{mm}$

$t$ : Time, s.

\section{Greek Symbols}

$\alpha$ : Thermal expansion coefficient, ${ }^{\circ} \mathrm{C}^{-1}$

$\beta$ : Search step size $\gamma:$ Conjugate-gradient coefficient

$\varepsilon_{i j}:$ Strains

$\xi: \quad$ Search directions

$\rho:$ Density, $\mathrm{kg} \mathrm{m}^{-3}$

$v$ : Poisson's ratio

$\sigma_{i j}$ : Thermal stresses, $\mathrm{MPa}$

$\sigma_{e}$ : The von Mises effective stress, $\mathrm{MPa}$

$\sigma_{s}:$ The yield stress, $\mathrm{MPa}$

$\delta_{i j}$ : Kronecker delta

$\delta$ : $\quad$ Error of the average temperature, ${ }^{\circ} \mathrm{C}$

$\Delta T$ : Temperature difference, ${ }^{\circ} \mathrm{C}$.

\section{Subscripts}

ave: Average value

$\infty$ : Environment condition

$m$ : Search steps in the CGM

$n$ : The variables number

$s$ : Surface of the H-beam.

\section{Disclosure}

Part of the abstract of this paper was presented in 19th International Conference on Aerospace, Mechanical, Automotive and Materials Engineering, May 11-12, Montreal, Canada, 2017.

\section{Conflicts of Interest}

The authors declare that there are no conflicts of interest regarding the publication of this paper.

\section{Acknowledgments}

This research was financially supported by the Ministry of Science and Technology and China Steel Corporation, Taiwan, under Contract no. MOST103-2622-E006-037. The authors are also grateful to Dr. Chao-Hua Wang of China Steel Corporation, Taiwan, for his valuable suggestions.

\section{References}

[1] C. J. Bettles and M. A. Gibson, "Current wrought magnesium alloys: strengths and weaknesses," Journal of Metals, vol. 57, pp. 46-49, 2005.

[2] Z. Li, D. Wu, and W. Lu, "Effects of rolling and cooling conditions on microstructure and mechanical properties of low carbon cold heading steel," Journal of Iron and Steel Research International, vol. 19, no. 11, pp. 64-70, 2012.

[3] C. Ouchi, "Development of steel plates by intensive use of TMCP and direct quenching processes," ISIJ International, vol. 41, no. 6, pp. 542-553, 2001.

[4] S. Endo and N. Nakata, "Development of Thermo-Mechanical Control Process (TMCP) and high performance steel in JFE Steel," JFE Technical Report, no. 20, pp. 1-7, 2015.

[5] N. Shikanai, S. Mitao, and S. Endo, "Recent development in microstructural control technologies through the thermomechanical control process (TMCP) with JFE Steel's highperformance plates," JFE Technical Report, no. 11, pp. 1-6, 2008. 
[6] H. W. Liu, J. Yan, D. H. Chen, and J. Q. Qian, "Finite element analysis of H-beam temperature field during cooling," Journal of Anhui University of Technology, vol. 20, pp. 4-7, 2003.

[7] Q. Liu, Y.Zang, Q. Qin, and J. Q. Zhao, "Analysis on temperature and thermal stress of h-beam during cooling," Metallurgical Equipment, vol. 167, pp. 17-20, 2008.

[8] X.-M. Zhao, F. Guo, L.-N. Wang, and D. Wu, "Effect of ultrafast cooling on cooling distortion for H-beam steel," Journal of Northeastern University, vol. 33, no. 7, pp. 949-952, 2012.

[9] F. Guo, X.-M. Zhao, L.-N. Wang, D. Wu, G.-D. Wang, and Z.L. Ning, "Effect of controlled cooling on microstructure and mechanical properties of H-beam," Journal of Iron and Steel Research International, vol. 20, no. 8, pp. 60-65, 2013.

[10] J. H. Ma, X. H. Yao, B. Tao, and S. Li, "Effects of cooling after rolling on thermal stress of H-beam steel," Hot Working Technology, vol. 43, pp. 121-123, 2014.

[11] G. M. Zhu, Y. L. Kang, W. Chen, J. L. Gui, and G. T. Ma, "Thermal mechanical coupled finite element analysis of thermal residual stress in h-beam's air cooling," Materials for Mechanical Engineering, vol. 32, pp. 77-80, 2008.

[12] Q. Liu, Y. Zang, Q. Qin, and Z. Q. Zhao, "Analysis on temperature and thermal stress of H-beam during cooling," Metallurgical Equipment, vol. 167, pp. 17-20, 2008.

[13] L. Zhao, X. G. Yu, G. B. Liao, and Y. L. Hu, "Simulation of Stress-strain of H-beam in control cooling process," Journal of University of Science and Technology Liaoning, vol. 34, pp. 466469, 2011.

[14] G. Zhu, Y. Kang, and G. Ma, "Simulation of residual stress in hot rolled large size H-beams," Materials Science Forum, vol. 704705, pp. 1370-1378, 2012.

[15] J. Y. Jang and Y. G. Gan, "Optimization analysis of controlled cooling process for h-shape steel beams," in Proceedings of the International Conference on Mechatronic, Automobile, and Environment Engineering, 2017.

[16] J. Y. Jang, L. F. Hsu, and J. S. Leu, "Optimization of the span angle and location of vortex generators in a plate-fin and tube heat exchanger," International Journal of Heat and Mass Transfer, vol. 67, pp. 432-444, 2013.

[17] J.-Y. Jang and Y.-C. Tsai, "Optimization of thermoelectric generator module spacing and spreader thickness used in a waste heat recovery system," Applied Thermal Engineering, vol. 51, no. 1-2, pp. 677-689, 2013.

[18] J.-Y. Jang and C.-C. Chen, "Optimization of louvered-fin heat exchanger with variable louver angles," Applied Thermal Engineering, vol. 91, pp. 138-150, 2015.

[19] J.-Y. Jang and J.-B. Huang, "Optimization of a slab heating pattern for minimum energy consumption in a walking-beam type reheating furnace," Applied Thermal Engineering, vol. 85, article no. 6547, pp. 313-321, 2015.

[20] X. K. Zhu and Y. J. Chao, "Numerical simulation of transient temperature and residual stresses in friction stir welding of 304L stainless steel," Journal of Materials Processing Technology, vol. 146, no. 2, pp. 263-272, 2004.

[21] JmatPro 9.0, Practical software for material properties, Sente Software Ltd, 2017.

[22] J. Wendelstorf, K.-H. Spitzer, and R. Wendelstorf, "Spray water cooling heat transfer at high temperatures and liquid mass fluxes," International Journal of Heat and Mass Transfer, vol. 51, no. 19-20, pp. 4902-4910, 2008.

[23] F. P. Incropera, D. P. Dewitt, T. L. Bergman, and A. S. Lavine, "Principles of Heat and Mass Transfer," in International Student Version, 7th edition. 

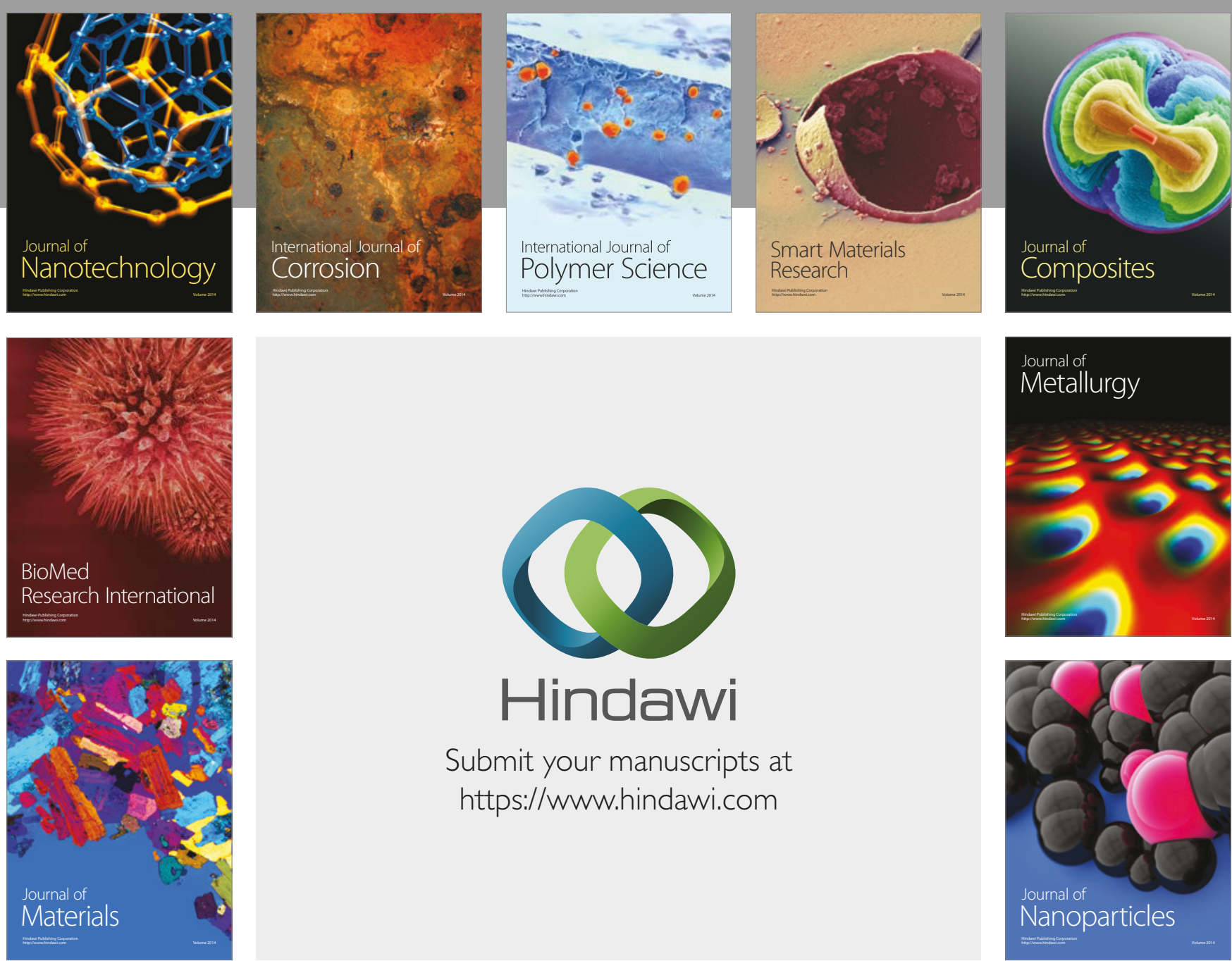

\section{Hindawi}

Submit your manuscripts at

https://www.hindawi.com
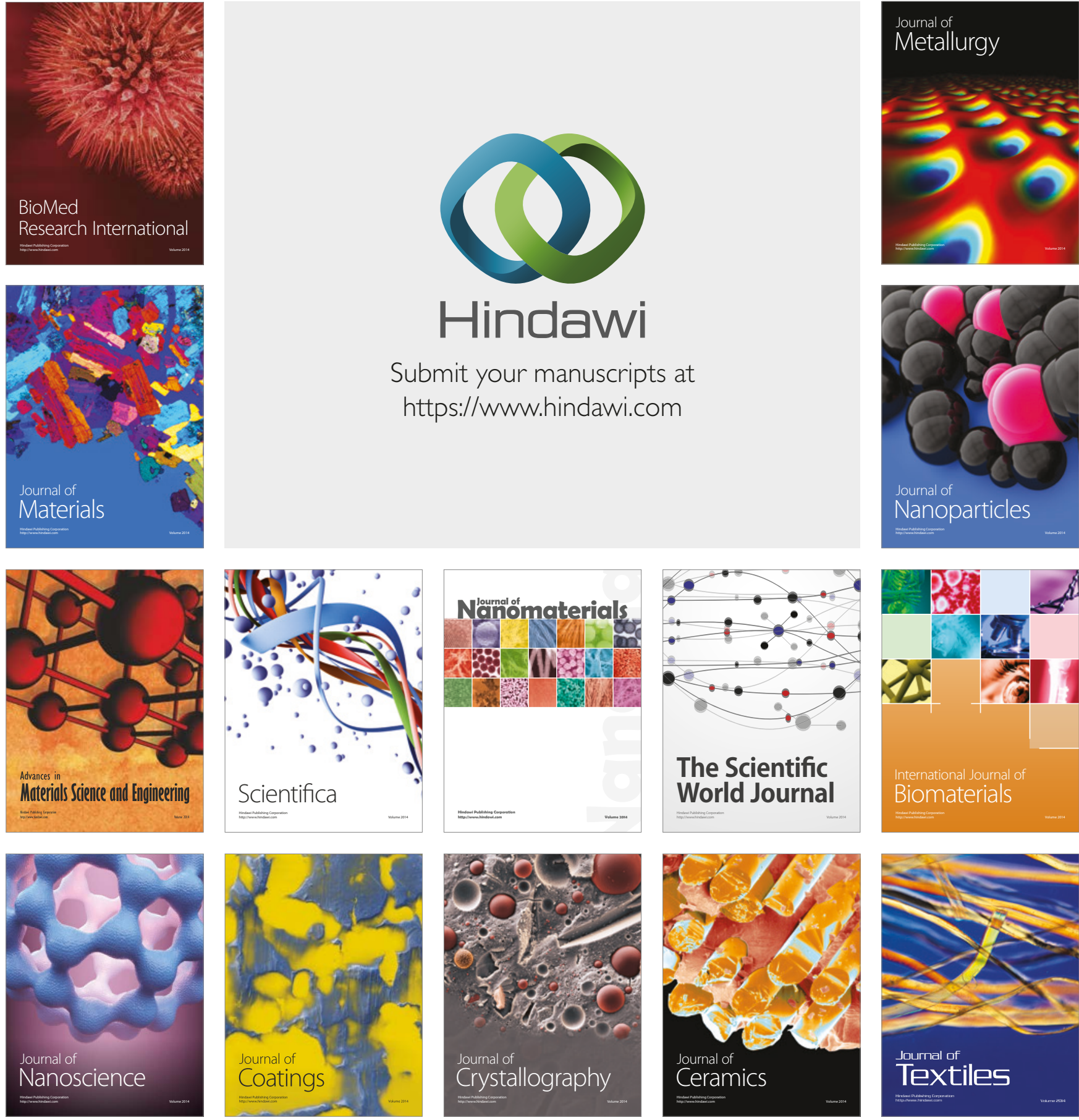

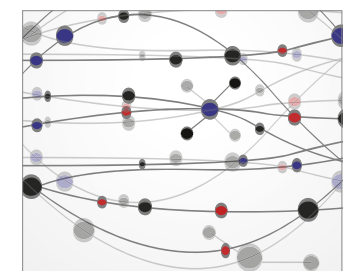

The Scientific World Journal
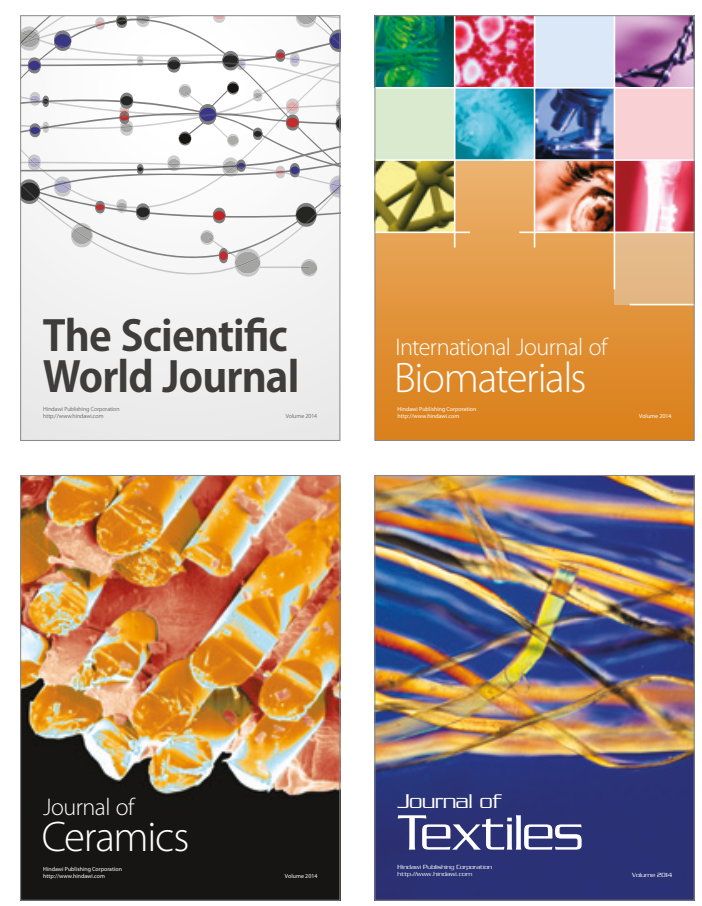